\title{
Head kinematics in patients with neck pain compared to asymptomatic controls: a systematic review
}

\author{
Esther Franov, Matthias Straub, Christoph M. Bauer and Markus J. Ernst ${ }^{*}$ (D)
}

\begin{abstract}
Background: Neck pain is one of the most common musculoskeletal disorders encountered by healthcare providers. A precise assessment of functional deficits, including sensorimotor control impairment, is regarded necessary for tailored exercise programmes. Sensorimotor control can be measured by kinematic characteristics, such as velocity, acceleration, smoothness, and temporal measures, or by assessing movement accuracy. This systematic review aims to identify movement tasks and distinct outcome variables used to measure kinematics and movement accuracy in patients with neck pain and present their results in comparison to asymptomatic controls.

Methods: Electronic searches were conducted in MEDLINE, PEDro, Cochrane Library and CINAHL databases from inception to August 2020. Risk of bias of included studies was assessed. Movement tasks and specific outcome parameters used were collated. The level of evidence for potential group differences in each outcome variable between patients with neck pain and controls was evaluated.
\end{abstract}

Results: Twenty-seven studies examining head kinematics and movement accuracy during head-aiming, functional and unconstrained movement tasks of the head were included. Average Risk of Bias of included studies was moderate. In total, 23 different outcome variables were assessed. A strong level of evidence for an increased movement time in idiopathic neck pain, and for an increased number of errors during head aiming tasks in both idiopathic and traumatic neck pain was found. Moderate evidence was found in traumatic neck pain for a decreased mean velocity, and peak acceleration, and for an increased reaction time, further for a decreased time on target and increased point deviation during head aiming tasks. Moderate evidence was found for decreased acceleration during unconstrained movements, too.

Results on the remaining movement task and outcome variables showed only limited, very limited or even conflicting level of evidence for patients with neck pain to differ from controls.

Conclusions: Sensorimotor control in NP in the way of kinematic and movement accuracy characteristics of head motion was examined in head aiming, functional or unconstrained movement tasks.

The results from this review indicate that for some characteristics that describe sensorimotor control, patients with NP differ from healthy controls.

Systematic review registration: PROSPERO registration number: CRD42020139083.

Keywords: Neck pain, Biomechanical phenomena, Head movements, Movement tasks, Whiplash

*Correspondence: markus.ernst@zhaw.ch

Zurich University of Applied Sciences, School of Health Professions, Institute

of Physiotherapy, Katharina-Sulzer-Platz 9, 8400 Winterthur, Switzerland give appropriate credit to the original author(s) and the source, provide a link to the Creative Commons licence, and indicate if changes were made. The images or other third party material in this article are included in the article's Creative Commons licence, unless indicated otherwise in a credit line to the material. If material is not included in the article's Creative Commons licence and your intended use is not permitted by statutory regulation or exceeds the permitted use, you will need to obtain permission directly from the copyright holder. To view a copy of this licence, visit http://creativecommons.org/licenses/by/4.0/. The Creative Commons Public Domain Dedication waiver (http://creativecommons.org/publicdomain/zero/1.0/) applies to the data made available in this article, unless otherwise stated in a credit line to the data. 


\section{Background}

Neck pain (NP) is a worldwide common and often recurrent disorder [1], with a 1-year prevalence of $39 \%$ and a point prevalence of $13 \%$ in the adult population [2]. NP can lead to disability [3] and generate high health care and economic costs, due to work absenteeism and presenteeism [4]. After low back pain, NP is one of the most common musculoskeletal disorders encountered by health professionals [5]. Current clinical guidelines recommend active rehabilitation, including exercises, to restore optimal function [6]. Tailored exercise programmes that address individual functional deficits are regarded superior to general physical activity [7] or general neck exercises [8] in reducing NP and disability. Therefore, a precise assessment of functional deficits in patients with NP should form the base for any individually-targeted active treatment approach [9].

Functional impairments frequently seen in patients with NP are a reduced range of motion [10], neuromuscular disturbances [11] and alterations in sensorimotor control [12].

Reimann and Lephard [13], described the sensorimotor control system, "incorporates all the afferent, efferent, and central integration and processing components involved in maintaining joint stability". Afferent information is given by the visual and vestibular systems, as well as the peripheral mechanoreceptors (e.g., muscle spindles). In patients with NP, cervical proprioceptive input can be altered by pain, direct damage to joints or muscles, functional impairments or morphological changes in neck muscles, and can consequently lead to impaired sensorimotor control [9]. Functional alterations that indicate impairment of the cervical sensorimotor control system in patients with NP have been reported for eye movement control [14], postural stability [15], eye-head [16] and head-trunk coordination [17], joint position[18], force- [19] and movement sense [20]. Impaired sensorimotor control can be observed in the movement itself by measuring and quantifying its kinematics [21]. Kinematics describe the motion of objects in space (such as the head) and the most common method is to study their position vector. This aspect has been examined widely in NP studies and is frequently described as range of motion, as well as other position vector-related measures $[10,21]$. Less well studied are the time derivatives of the position vector, such as velocity (1st derivative), acceleration (2nd derivative) or jerk (3rd derivative), which can give further insight into the quality of the movement. Another movement related aspect is the aforementioned movement sense, which can be assessed by the ability to precisely follow a given path with a head mounted point projection, further described here as movement accuracy.
Two recent reviews on kinematics of head movements in patients with NP compared to a control group reported either on velocity [10] or on functional tasks [22], however, there has been no review examining further kinematic quantities such as acceleration, jerk or other time-domain related parameters, and for different kinds of movement tasks.

Further reviews on the topic of sensorimotor control in NP focussed primarily on position sense, but give an only incomplete overview regarding movement accuracy $[23,24]$. So far, no review has examined which of various variables describing kinematics and movement accuracy might be best suited for distinguishing patients with NP from asymptomatic controls.

Accordingly, this systematic review aims to give an overview of movement tasks and outcome measures used to examine head kinematics and movement accuracy in patients with NP compared to asymptomatic controls through critical appraisal of the published literature. An additional aim is to examine the evidence for their ability to discriminate between individuals with and without NP.

\section{Methods \\ Review registration}

The protocol for this review was registered with the International Prospective Register of Systematic Review (PROSPERO) in April 2020 (CRD42020139083). The review process was conducted using the guidelines of The Preferred Reporting Items for Systematic Reviews and Meta- Analyses (PRISMA) [25].

\section{Publications and participants}

Studies on adults of both sexes with acute, subacute, or chronic idiopathic and traumatic (whiplash associated disorder $=$ WAD) NP were included in the review. Studies with focus on specific NP conditions, e.g., radiculopathy, myelopathy, or post-surgical studies, were excluded. Studies could be of cross-sectional or longitudinal nature but had to incorporate a healthy control group.

Only full text studies published in English were included. No limitation on publication date was applied.

\section{Outcomes}

Outcome measures had to be reported as parameters of head motion kinematics or movement accuracy for the NP and the control group.

\section{Search strategy and study selection}

Electronic searches were conducted in the databases MEDLINE (via Ovid SP), PEDro, Cochrane Library and CINAHL (via ebscohost.com) from inception until August 2020. 
MeSH terms that described the NP conditions, biomechanical phenomena, measurement properties and study design were selected by two reviewers (EF, MS). The complete search strategy used for MEDLINE is reported in Additional file 1.

Supplemental, online platforms of large publishers, including ScienceDirect, Informa Healthcare, SpringerLink and Wiley Online Library, were searched using wellknown authors in the field. Reference lists of included studies were hand-searched, and Web of Science was checked for citations of included studies. Eligible citing and referenced studies were included until September 2020.

Studies identified in the search were downloaded into EndNote X9 (Clarivate Analytics, USA) and duplicates were removed. Study selection was conducted independently by two reviewers (EF and MS) and interrater agreement was calculated using Cohen's kappa. Raters discussed any discrepancies and as required, consulted a third author (MJE) until consensus was reached. Identified publications were screened primarily by title and abstract. The selected studies were further assessed for eligibility by full text reading and the reasons for study exclusion were documented (see Table 1 at the end).

\section{Assessment of methodological quality}

Assessment of the methodological quality of included studies was conducted using an adapted form of the Quality Assessment Tool for Observational Cohort and Cross-Sectional Studies of the U.S. National Heart, Lung, and Blood Institute [53]. This tool has been used in similar systematic reviews to assess a potential risk of bias (RoB) [22, 24]. After pilot testing, the original form was tailored to fit the case control design of included studies and the review's aims. In total fourteen items remained.

All items were compared by both reviewers for their weight in assessing risk of bias (RoB). It was decided to double the value of six items addressing the RoB more exclusively (items $5,6,8-10,13$ ), resulting in a maximum score of twenty points. For the total methodological quality rating (out of a maximum score of 20 points), a score of $>13$ was interpreted as the study having a low RoB; a score from 7 to 13 a moderate RoB; and a score $<7$ a high RoB.

A detailed description of the implemented adaptations is presented in Additional file 2.

Quality assessment was performed by two independent reviewers (EF and MS). A third independent reviewer (MJE) was consulted in case of disagreement.

\section{Data extraction and synthesis}

A data extraction form was developed. Two reviewers independently completed the form for each study and cross-checked the extracted data. Data included information on sampling procedures, sample sizes, participant data, measurement methods, outcome variables and RoB. If results were presented in figures only, WebPlotDigitizer would have been used to extract numerical data [54]. This semi-automatic extraction tool has previously been proven reliable and valid [55]. Differences between groups were considered statistically significant, if a hypothesis testing revealed a $p$-value $<0.05$.

Included studies were assessed for methodological homogeneity, considering their potential for meta-analysis.

Findings were summarized for any outcome variable and across studies and labelled with a corresponding "Level of evidence", according to an adapted classification system, mentioned by the method guidelines for systematic reviews in the Cochrane collaboration Back Review Group [56] (Table 2). The number and methodological quality of studies, and the consistency of results between studies, were considered.

The summary of findings and level of evidence for kinematic and movement accuracy measures are presented separately for idiopathic NP (INP) and WAD, each group in comparison to healthy controls. For outcome assessed by studies without differentiation of NP onset (in future described as "unclassified NP", the summary of findings and level of evidence was evaluated together with the results of INP studies.

Consistent findings were defined a priori as differences of NP subgroups compared to healthy controls indicating in the same direction.

\section{Results}

\section{Literature search results}

Database and hand-searching identified 1'000 publications. After removal of duplicates, 870 records remained. These were further screened by title and abstract reading, leading to 814 studies being excluded, with an interrater agreement for exclusion of .85 . No aspects of either kinematics or movement accuracy were examined and/or participants suffered from specific NP conditions were the main reasons for exclusion. Subsequently, 56 studies were selected for full text reading. Finally, 27 studies were included in the review with the full agreement of both reviewers (see Table 1: List of excluded studies).

Figure 1 illustrates the flow of studies through the selection process.

\section{Methodological quality of included studies}

The overall rating of the methodological quality of included studies ranged from 4 to 15 (out of 20 points), with an average score across studies of 9.5, indicating an overall moderate RoB. Cohen's kappa for interrater 
Table 1 List of excluded studies with reason

\section{Study}

Reason for exclusion

Alsultan F, Cescon C, De Nunzio AM, Barbero M, Heneghan NR, Rushton A, et al. Variability of the helical axis during active No outcome of interest cervical movements in people with chronic neck pain. Clinical biomechanics (Bristol, Avon). 2019;62:50-7 [26].

Bahat HS, Croft K, Hoddinott A, Carter C, Treleaven J. Remote kinematic e-training for patients with chronic neck pain, a randomised controlled trial. Manual Therapy. 2016;25:e35 [27]

Bahat HS, Sprecher E, Sela I, Treleaven J. Neck motion kinematics: an inter-tester reliability study using an interactive neck No control group VR assessment in asymptomatic individuals. European Spine Journal. 2016;25 (7):2139-48 [28].

de Zoete RMJ, Osmotherly PG, Rivett DA, Snodgrass SJ. Cervical Sensorimotor Control Does Not Change Over Time and Is Not Related to Chronic Idiopathic Neck Pain Characteristics: A 6-Month Longitudinal Observational Study. Physical therapy. 2020;100 (2):268-82 [29]

Geisinger D, Ferreira E, Suarez A, Suarez H. Dynamic modeling and experimental results for a head tilt response. Conference Proceedings: Annual International Conference of the IEEE Engineering in Medicine \& Biology Society. 2010;2010:2986-9 [30].

Goncalves C, Silva AG. Reliability, measurement error and construct validity of four proprioceptive tests in patients with chronic idiopathic neck pain. Musculoskeletal science \& practice. 2019;43:103-9 [31]

Grip H, Jull G, Treleaven J. Head eye co-ordination using simultaneous measurement of eye in head and head in space movements: potential for use in subjects with a whiplash injury. J Clin Monit Comput. 2009;23:31-40 [32].

Jull G, Amiri M, Bullock-Saxton J, Darnell R, Lander C. Cervical musculoskeletal impairment in frequent intermittent headache. Part 1: Subjects with single headaches. Cephalalgia. 2007;27 (7):793-802 [33].

Kristjansson E, Dall'alba P, Jull G. Cervicocephalic kinaesthesia: reliability of a new test approach. Physiotherapy Research International. 2001;6 (4):224-35 [34].

Kristjansson E, Björnsdottir SV, Oddsdottir GL. The long-term course of deficient cervical kinaesthesia following a whiplash injury has a tendency to seek a physiological homeostasis. A prospective study. Man Ther. 2016;22:196-201 [35]

Lascurain-Aguirrebena I, Newham DJ, Galarraga-Gallastegui B, Critchley DJ. Differences in neck surface electromyography, kinematics and pain occurrence during physiological neck movements between neck pain and asymptomatic participants. A cross-sectional study. Clinical biomechanics (Bristol, Avon). 2018;57:1-9 [36]

Meisingset I, Stensdotter AK, Woodhouse A, Vasseljen O. Changes in neck motion and motor control and associations with neck pain in patients with non-specific neck pain. Physiotherapy. 2015;101:e994 [37]

Meisingset I, Stensdotter AK, Woodhouse A, Vasseljen O. Neck motion, motor control, pain and disability: A longitudinal study of associations in neck pain patients in physiotherapy treatment. Manual Therapy. 2016;22:94-100 [38]

Oddsdottir GL, Kristjansson E. Two different courses of impaired cervical kinaesthesia following a whiplash injury. A oneyear prospective study. Man Ther. 2012;17 (1):60-5 [39]

Roijezon U, Bjorklund M, Bergenheim M, Djupsjobacka M. A novel method for neck coordination exercise--a pilot study on persons with chronic non-specific neck pain. J Neuroeng Rehabil. 2008;5:36 [40]

Rudolfsson T, Djupsjobacka M, Hager C, Bjorklund M. Effects of neck coordination exercise on sensorimotor function in chronic neck pain: a randomized controlled trial. Journal of Rehabilitation Medicine 2014 Oct;46 (9):908-914. 2014 [41]

Saadat M, Salehi R, Negahban H, Shaterzadeh MJ, Mehravar M, Hessam M. Traditional physical therapy exercises combined with sensorimotor training: the effects on clinical outcomes for chronic neck pain in a double-blind, randomized controlled trial. Journal of Bodywork and Movement Therapies 2019 Oct;23 (4):901-907. 2019 [42]

Sarig Bahat H, Weiss PL, Sprecher E, Krasovsky A, Laufer Y. Do neck kinematics correlate with pain intensity, neck disability or with fear of motion? Journal of the Israeli Physical Therapy Society (JIPTS). 2014;16 (2):38- [43]

Sarig Bahat H, Takasaki H, Chen X, Bet-Or Y, Treleaven J. Cervical kinematic training with and without interactive VR training for chronic neck pain - a randomized clinical trial. Manual Therapy. 2015;20 (1):68-78 [20]

Bahat HS, Croft K, Carter C, Hoddinott A, Sprecher E, Treleaven J. Remote kinematic training for patients with chronic neck pain: a randomised controlled trial. European Spine Journal. 2018;27 (6):1309-23 [44]

Treleaven J, Croft K, Carter C, Hoddinott A, Sarig-Bahat H. Are functional complaints relating to neck motion related to altered cervical kinematics in those with neck pain? Musculoskeletal Science and Practice. 2017;28:e12 [45]

Treleaven J, Chen X, Sarig Bahat H. Factors associated with cervical kinematic impairments in patients with neck pain. Manual Therapy. 2016;22:109-15 [46]

Treleaven J, Takasaki H, Grip H. Altered trunk head co-ordination in those with persistent neck pain. Musculoskeletal Science and Practice. 2019;39:45-50 [17]

Tsang SM, Szeto GP, Lee RY. Relationship between neck acceleration and muscle activation in people with chronic neck pain: Implications for functional disability. Clinical Biomechanics. 2016;35:27-36 [47]

Waeyaert P, Jansen D, Bastiaansen M, Scafoglieri A, Buyl R, Schmitt M, et al. Three-dimensional Cervical Movement Characteristics in Healthy Subjects and Subgroups of Chronic Neck Pain Patients Based on Their Pain Location. Spine. 2016;41 (15):E908-14 [48]

Werner IM, Ernst MJ, Treleaven J, Crawford RJ. Intra and interrater reliability and clinical feasibility of a simple measure of cervical movement sense in patients with neck pain. BMC Musculoskeletal Disorders. 2018;19 (1):358 [49]

Sample duplicate

No outcome of interest

No outcome of interest

Missing data

No outcome of interest

No control group

No control group

No outcome of interst

Conference abstract

No control group

No control group

No control group

No control group

No control group

No control group

No control group

No control group

Conference abstract

No control group

No outcome of interest

Sample duplicate

Missing data

No control group 
Table 1 (continued)

\begin{tabular}{|c|c|}
\hline \multicolumn{2}{|l|}{ Study } \\
\hline \multicolumn{2}{|c|}{$\begin{array}{l}\text { Williams G, Sarig-Bahat H, Williams K, Tyrrell R, Treleaven J. Cervical kinema } \\
\text { patients with neck pain: A pilot study. Journal of Vestibular Research. } 2017\end{array}$} \\
\hline \multicolumn{2}{|c|}{$\begin{array}{l}\text { Woltring HJ, Long K, Osterbauer PJ, Fuhr AW. Instantaneous helical axis es } \\
\text { ics for whiplash diagnostics. Journal of Biomechanics. 1994;27 (12):1415-3 }\end{array}$} \\
\hline \multirow{2}{*}{\multicolumn{2}{|c|}{$\begin{array}{l}\text { Zito G, Jull G, Story I. Clinical tests of musculoskeletal dysfunction in the } \\
\text { Therapy. 2006;11 (2):118-29 [52]. } \\
\\
\text { Table } 2 \text { Level of evidence }\end{array}$}} \\
\hline & \\
\hline Level of evidence & Criteria \\
\hline Strong & $\begin{array}{l}\text { Multiple studies with low RoB } \\
\text { AND consistent findings across all studies }\end{array}$ \\
\hline Moderate & $\begin{array}{l}\text { One study with low RoB AND/OR multiple studies } \\
\text { of moderate RoB AND consistent findings across } \\
\text { all studies }\end{array}$ \\
\hline Limited & $\begin{array}{l}\text { One study with moderate RoB } \\
\text { AND consistent findings across all studies }\end{array}$ \\
\hline Very limited & One study with high RoB \\
\hline Conflicting & Inconsistent findings between studies \\
\hline
\end{tabular}

RoB Risk of Bias

reliability, and before consensus discussion, was .81. Disagreements between the two reviewers could be solved by discussion (See Table 3 for details on critical appraisal). All studies stated a clear review question, and only three $[61,63,79]$ did not provide appropriate descriptive data. There was a lack of information to prevent selection bias in all studies, due to missing information on the sampling process, population characteristics or participation rate. Only three studies provided a sample size calculation [57, $59,75]$. Two studies gave no description of the definition for the control group [71, 83]. Eleven studies had missing information on the reliability of outcome measurements [57, 58, 61, 63, 67, 72-74, 77, 82, 83]. Confounding occurred, either by the application of different exclusion criteria across groups, by not having controlled for factors such as age, sex or comorbidities during the selection process. Another source of confounding was an insufficient control of further movement task specifications, such as speed, or displacement. Only five studies gave sufficient information for these RoB items $[60,75,76,78$, 79]. One study [70] mentioned that the statistician was not blinded, none of the other studies reported on blinding of outcome assessors or statisticians.

\section{Study characteristics}

\section{Publications and participants}

All 27 included studies were cross-sectional studies, with sample sizes ranging from 20 to 167 . Nine studies reported on INP exclusively $[58,59,63,66,67,71,72,78$, 79], eight studies on WAD only [57, 61, 64, 68-70, 77, 80], six studies assessed outcomes for WAD and INP separately $[60,62,65,75,76,81]$, while another four studies reported on unclassified NP [73, 74, 82, 83]. Eight studies, that included patients after WAD [60, 69, 70, 73-77] did not report on a specific grade according to the Quebec Task classification [84], while another eight studies included patients after WAD grade I [61, 62, 64, 65, 68, $81]$, grade II $[57,61,62,64,65,68,80,81]$, or grade III $[57,61]$.

In total, 1'847 participants were examined across included studies, of which 911 were healthy controls, 631 participants with NP (INP and unclassified NP) and 305 participants with WAD. The average age of participants with NP ranged from 25.3 to 51.0 years; for participants with WAD from 27.0 to 49.0 years; and for controls from 19.9 to 50.0 years. Female participation rate dominated, with an average of $63 \%$ in the INP and unclassified NP, $72 \%$ in the WAD, and $58 \%$ in the control group. Average pain intensity, either reported as mean or median value, were transferred to a 0 to 100 measurement scale, and ranged from 20.1 to 60.0 for participants with INP and unclassified NP and from 29.0 to 66.1 for participants with WAD, likewise average disability, if provided, ranged from 9.5 to $37 \%$ for participants with INP and unclassified NP and from 25.2 to $45 \%$ for participants with WAD [57-83]. Table 4 provides further information on characteristics including studies' criteria for being regarded as participant with NP or asymptomatic.

Symptom duration in seventeen studies lasted for at least 6 weeks or longer $[57-60,64,65,68,70,71,73,74$, $76-79,81,83]$.

\section{Movement tasks examined in included studies (Table 5)}

The movement tasks used to assess kinematics were either head-aiming [58-61, 63-65, 67, 68, 70, 73-75, 81], functional [62, 77, 79], or unconstrained tasks [57, 62, 66, $67,69,71,72,76,78,80,82,83]$. Movement accuracy was assessed exclusively by head aiming tasks [58-61, 63-65, $67,68,70,73-75,81]$. 


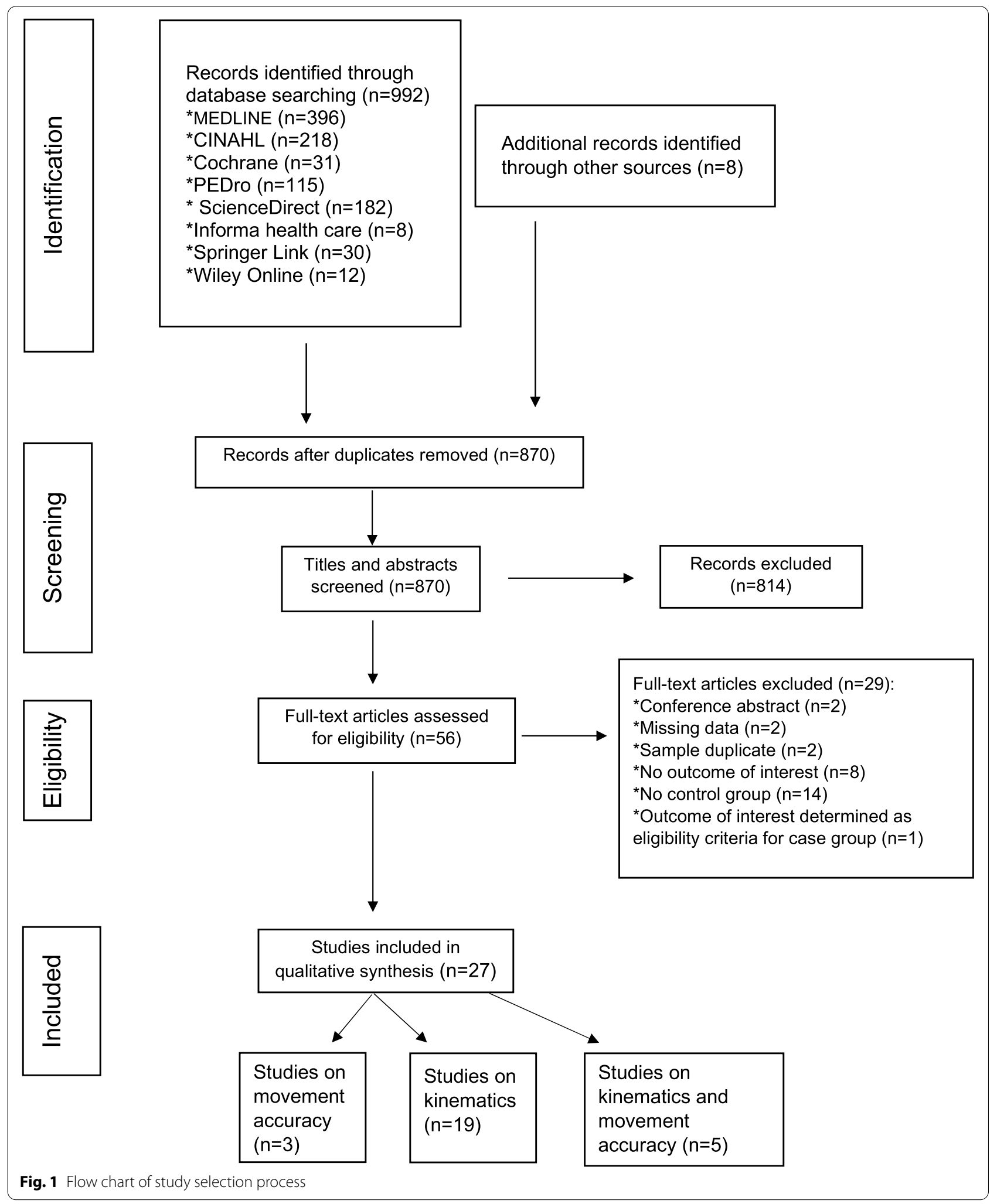




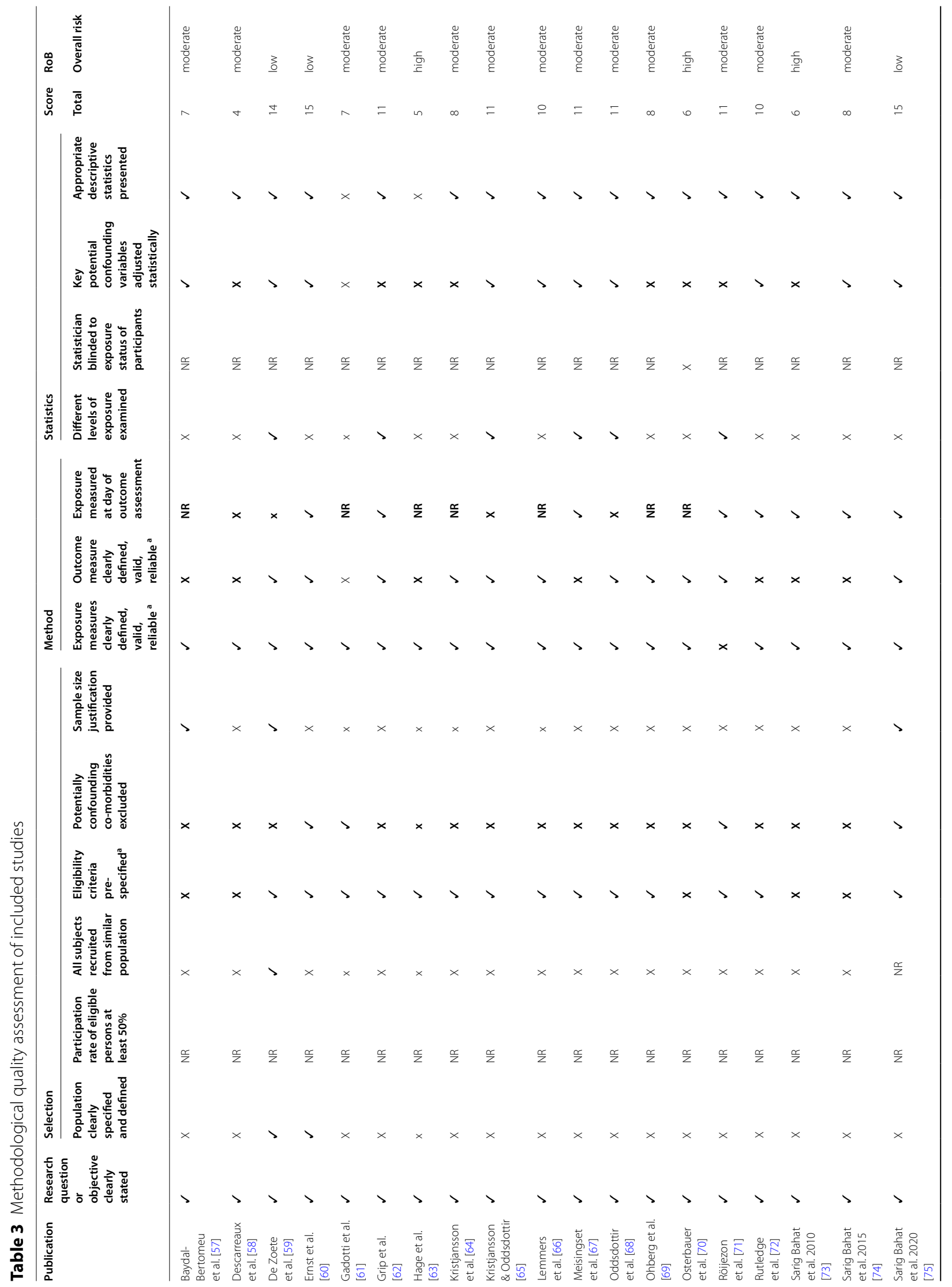




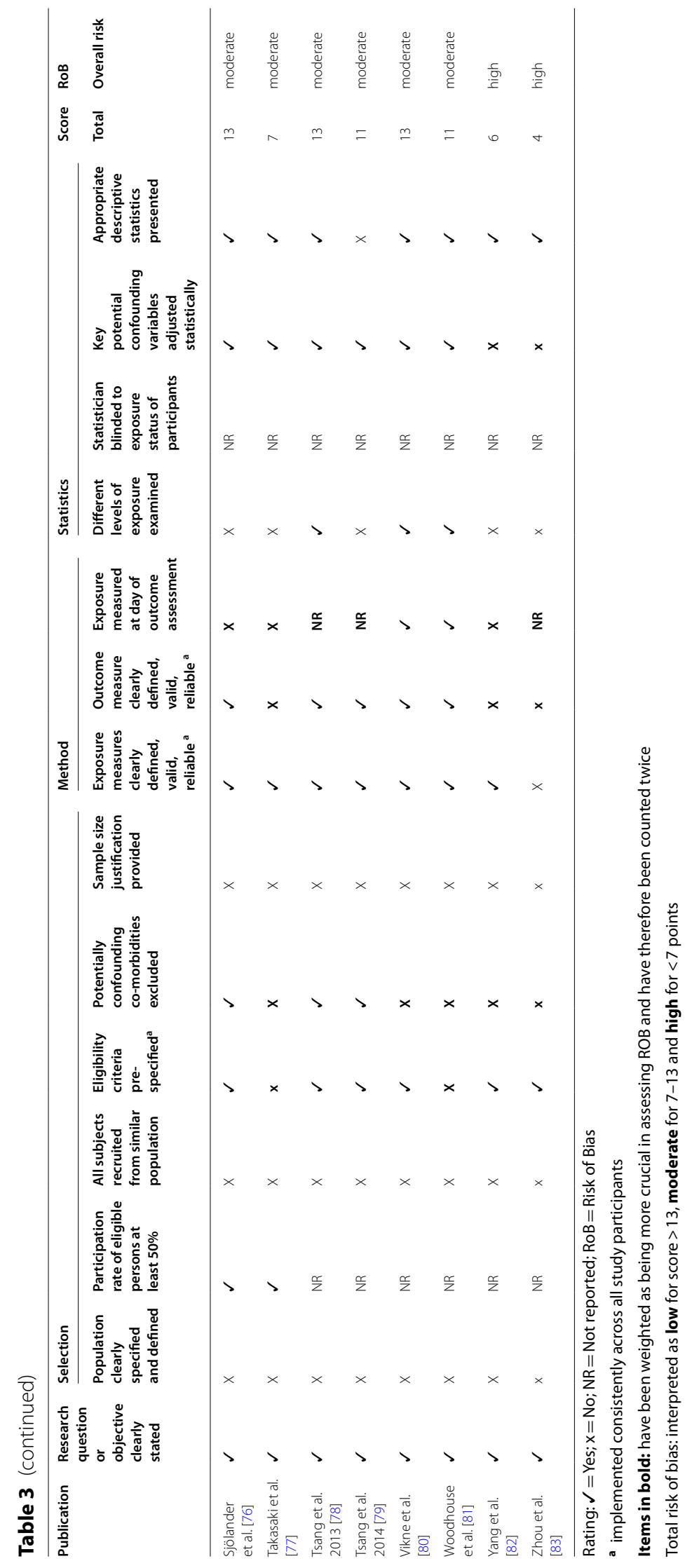




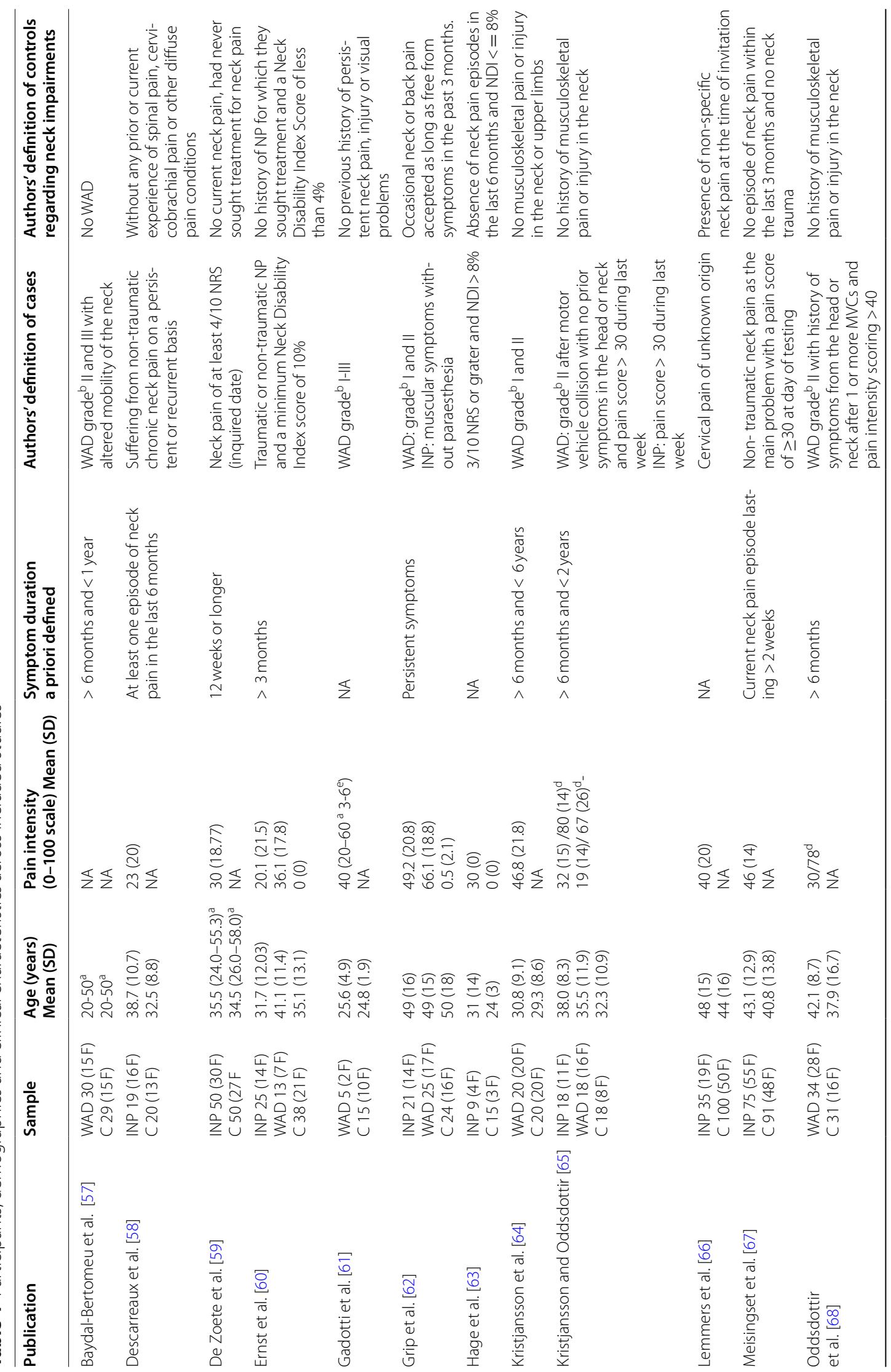




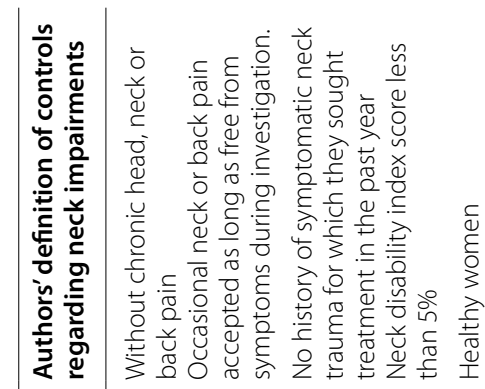

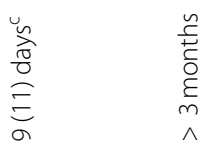

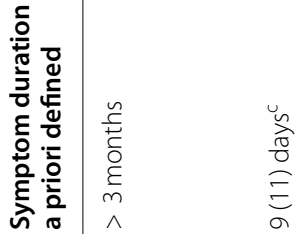

जิ

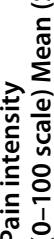

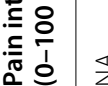

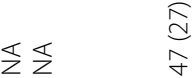

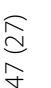

$\stackrel{\substack{0 \\ \dot{y}}}{\Sigma}$
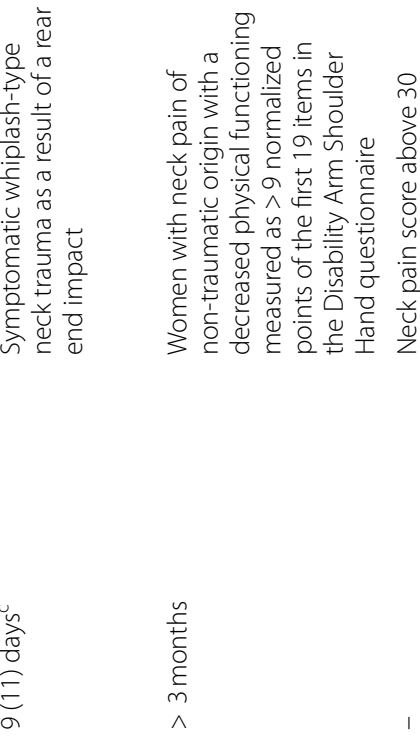
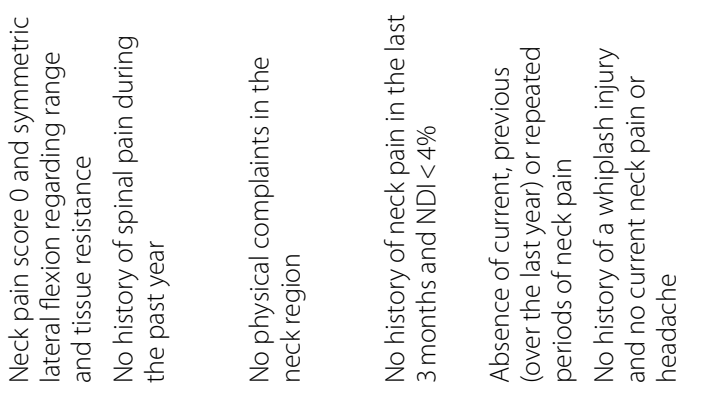

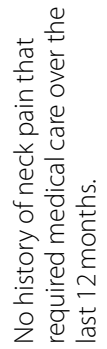

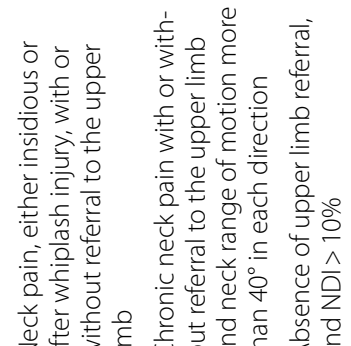

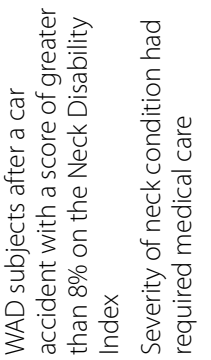
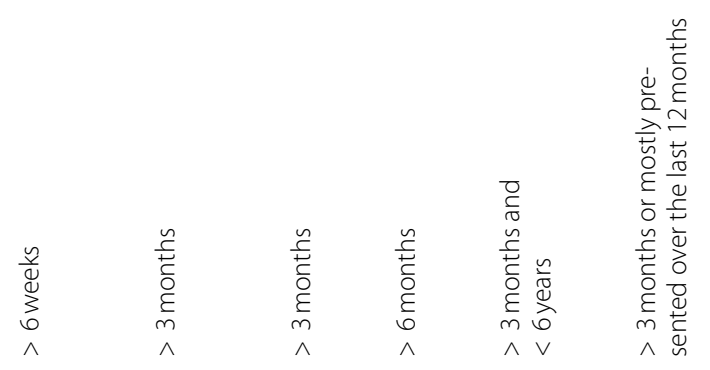

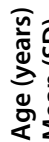

जิ

宅 ฐँ

im

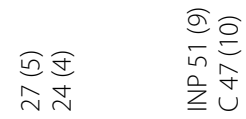

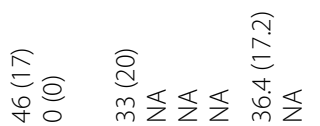

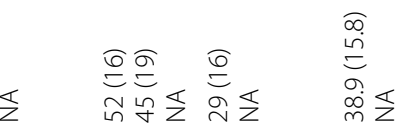

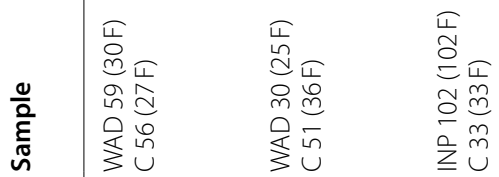

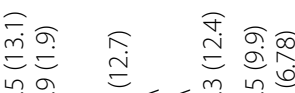

जू

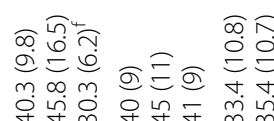

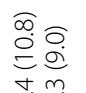

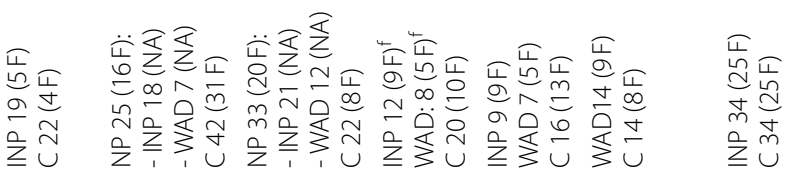




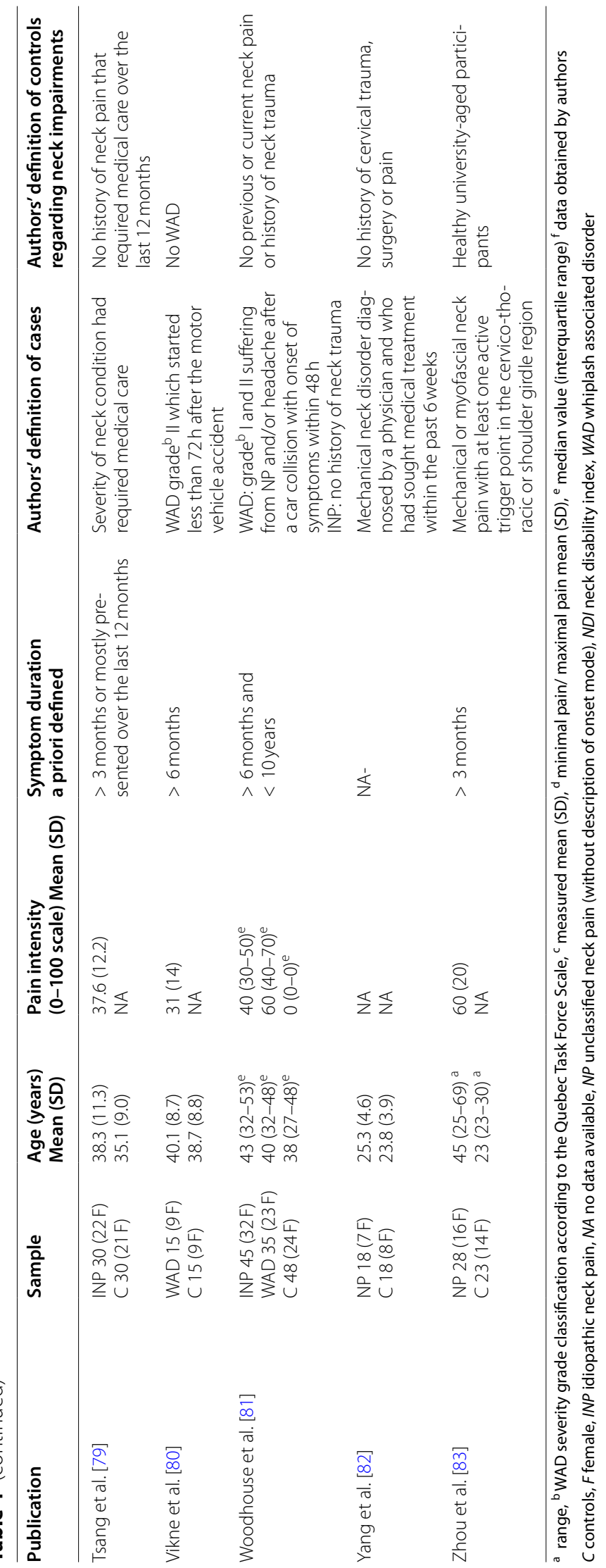


Table 5 Movement tasks and further specifications

\begin{tabular}{|c|c|c|c|c|}
\hline Tasks & & Specified Outcome variables & Task specifications & \\
\hline \multirow[t]{2}{*}{ Head aiming $(n=14)$} & Tracking $(n=10)$ & $\begin{array}{l}\text { Velocity variables }(n=2) \\
\text { Temporal variables }((n=2) \\
\text { Movement smoothness }(n=2) \\
\text { Movement accuracy }(n=8)\end{array}$ & $\begin{array}{l}\text { Starting position } \\
\text { Repetitions }\end{array}$ & $\begin{array}{l}\text { Tracking cursor speed } \\
\text { Tracking pattern } \\
\text { Track predictable/ unpredictable }\end{array}$ \\
\hline & Pointing $(n=5)$ & $\begin{array}{l}\text { Velocity variables }(n=3) \\
\text { Acceleration variables }(n=1) \\
\text { Temporal variables }(n=4) \\
\text { Movement smoothness }(n=2)\end{array}$ & & $\begin{array}{l}\text { Target size } \\
\text { Target speed } \\
\text { Target direction } \\
\text { Target predictable/ unpredictable }\end{array}$ \\
\hline Functional $(n=3)$ & & $\begin{array}{l}\text { Velocity variables }(n=2) \\
\text { Acceleration variables }(n=1)\end{array}$ & & $\begin{array}{l}\text { Task predictable/ unpredictable } \\
\text { Task speed }\end{array}$ \\
\hline Unconstrained $(n=12)$ & & $\begin{array}{l}\text { Velocity variables }(n=10) \\
\text { Acceleration variables }(n=4) \\
\text { Temporal variables }(n=5) \\
\text { Movement smoothness }(n=7)\end{array}$ & & $\begin{array}{l}\text { Cyclic/ single motion } \\
\text { Motion direction } \\
\text { Eyes open/ closed } \\
\text { Speed instruction } \\
\text { Motion range instruction }\end{array}$ \\
\hline
\end{tabular}

( $n=$ number of studies)

During head-aiming tasks, participants wore a headmounted device that projected a visible point on a screen or wall in front of them. They controlled the position of that signal by moving their head either accurately along a trajectory (tracking) [59, 60, 64, 65, 67, 68, 70, 73-75, 81], or towards a target point (pointing) [58,61, 63, 73-75]. These target points and trajectory paths were either visible before and during the tasks (predictable) $[58,60,63$, $70,79,81]$ or appeared unpredictably (unpredictable) [61, $64,65,68,73,74,77]$.

Three studies examined head kinematics while participants performed functional tasks, such as driving in a simulator, catching a ball, or lifting a weight [62, 77, 79]. During unconstrained movement tasks, participants were asked to move their head in a specific direction like in rotation or extension [57, 62, 66, 67, 69, 71, 72, 76, 78, 80, 82, 83]. Further tasks specifications were used in relation to speed, repetitions, or the amplitude of movement. (See Table 5).

\section{Measurement devices}

To assess kinematics, electromagnetic motion tracking systems were used in thirteen studies [59, 64-68, 71, 73, 78-82], optical motion capture systems in eight studies $[57,58,61-63,69,70,72]$, virtual reality tracking systems in three studies [73-75], and inertial motion capture systems in another three studies [74, 77, 83].

For movement accuracy assessments, five studies used an electromagnetic tracking system [59, 64, 65, 67, 68], two studies a virtual reality tracking system $[74,75]$ and two studies a head-mounted laser pointer $[60,75]$.

\section{Outcome measures}

Table 6 provides an overview of specified outcome measures and variables reported in included studies. Five groups of outcome measures emerged that describe different sensorimotor control alterations related to NP.

Velocity and acceleration measures were assessed in eighteen studies and summarised as discrete or continuous variables calculated either from velocity [57, 62, $63,67,69-80,82]$ or acceleration time series $[57,63$, 78-80, 83].

Temporal measures investigated in eleven studies incorporated time-related variables and were calculated as duration of different phases of a movement such as acceleration or deceleration [58], as ratio of phase durations $[71,73,74,80]$, and in addition as time to complete $[58,60,61,75,82,83]$, or to initiate a task $[61,69,73]$.

Movement smoothness measured in eleven studies $[57,66,68,71,73,74,76,80-83]$, considered the degree of interruptions affecting the continuous and smooth evolvement of a movement. Most of the variables used were velocity or jerk-based; of these, some were dimensionless, which means. Independent of the movement amplitude and duration, such as the normalized jerk cost $[68,76,80,83]$, while others were not, like the root mean square jerk [66]. Speed index of deviation quantified the degree to which a movement's speed was optimised, to minimise jerk [71]. Other variables of movement smoothness measured the complexity found in a movement, with complexity reflecting how a movement evolves from a series of sub-movements [57]. Spectral entropy, which measures the complexity in the power spectrum of a movement, was also used for this purpose [82].

Movement accuracy measures used in eight studies $[59,60,64,65,67,68,74,75]$ described the proximity of a movement to a given target area or target trajectory 
Table 6 Summary of outcome measures

\begin{tabular}{|c|c|c|c|}
\hline Outcome measure & No. of studies & Specified outcome variable & No. of studies \\
\hline \multirow[t]{3}{*}{ Velocity } & 18 & Mean velocity & 10 \\
\hline & & Peak velocity & 12 \\
\hline & & Normalized peak amplitude & 1 \\
\hline \multirow[t]{4}{*}{ Acceleration } & 6 & Mean acceleration & 1 \\
\hline & & Peak acceleration & 4 \\
\hline & & Peak deceleration & 2 \\
\hline & & Magnitude of circumduction vector & 1 \\
\hline \multirow[t]{5}{*}{ Temporal } & 11 & Movement time & 6 \\
\hline & & Reaction time & 3 \\
\hline & & Acceleration phase duration & 1 \\
\hline & & Deceleration phase duration & 1 \\
\hline & & Ratio of phase durations & 4 \\
\hline \multirow[t]{8}{*}{ Movement smoothness } & 11 & Normalized jerk cost & 4 \\
\hline & & Root mean square jerk & 1 \\
\hline & & Number of jerk peaks & 1 \\
\hline & & Root mean square velocity & 1 \\
\hline & & Number of velocity peaks & 2 \\
\hline & & Speed index of deviation & 1 \\
\hline & & Spectral entropy & 1 \\
\hline & & Harmonicity & 1 \\
\hline \multirow[t]{3}{*}{ Movement accuracy } & 8 & Number of errors & 2 \\
\hline & & Point deviation & 7 \\
\hline & & Time on target & 2 \\
\hline
\end{tabular}

and outcome variables used were counting the numbers of errors while following a given trajectory $[60,75]$, calculating the point deviation from a tracking path [59, $64,65,67,68,74,75]$, and measuring the time the trajectory remained on a target $[65,68]$.

\section{Summary of findings}

Clinical and methodological heterogeneity regarding participant characteristics, task specifications, and kinematic or movement accuracy outcome variables was large for all studies. Consequently, findings were summarized qualitatively only, and are presented in Tables 7, 8, 9, 10 and 11. All results are presented for NP and its subgroups (INP or WAD), when compared to control participants.

\section{Velocity variables (Table 7)}

Ten studies assessed mean velocity of head motion in participants as outcome variable $[62,63,69,70,72-75$, $78,80]$. Seven studies on INP or unclassified NP showed a conflicting level of evidence $[62,63,72-75,78]$. In contrast, those four studies on WAD subjects only, showed a decrease in mean velocity, and resulted in a moderate level of evidence $[62,69,70,80]$. Twelve studies on peak velocity demonstrated a conflicting level of evidence for all NP groups $[57,63,67,69,71,73,74,76,77,79,80$,
82], with four studies of moderate and high RoB, indicating no differences in peak velocity in NP $[63,76,77$, 82], while, in contrast to these, eight studies described a decreased peak velocity in NP $[57,67,69,71,73,74,79$, 80]. One study presented a ratio of peak to mean velocity (normalized peak amplitude) in INP, and found no differences [71].

\section{Acceleration variables (Table 8)}

One study of moderate quality looked at mean acceleration and found that patients with INP showed a reduced acceleration, that resulted in a limited level of evidence [78]. Two studies were investigating peak acceleration in INP, and showed inconsistent results, leading to a conflicting level of evidence [63, 79]. While another two studies that focused on patients with WAD showed peak acceleration to be lowered [57, 80]. Two studies were assessing peak deceleration which led to a very limited level of evidence for INP to move with similar [63], and a limited level of evidence for WAD to move with decreased peak deceleration [80]. A very limited level of evidence was found for a decreased Magnitude of Circumduction vectors, as one study of high RoB assessed this outcome variable [83]. 
Table 7 Outcome Summary for Velocity variables

\begin{tabular}{|c|c|c|c|c|c|}
\hline \multicolumn{6}{|l|}{ Mean Velocity } \\
\hline \multicolumn{6}{|c|}{$\begin{array}{l}\text { Summary of findings for NP/INP: } \\
\text { - Inconsistent findings on mean velocity in NP/INP patients compared to healthy controls } \\
\text { - Level of evidence: conflicting } \\
\text { Summary of findings for WAD: } \\
\text { - Decreased mean velocity in WAD compared to healthy controls } \\
\text { - Level of evidence: moderate }\end{array}$} \\
\hline Publication & Sample & Task & Task specifications & Results compared to $C$ & Risk of Bias \\
\hline Sarig Bahat et al. [75] & $\begin{array}{l}\text { NP } 20 \\
\text { C } 20\end{array}$ & Head aiming; Tracking & $\begin{array}{l}\text { Speed: Self-preferred } \\
\text { Tracking path: Predictable } \\
\text { Pattern: Zig Zag }\end{array}$ & Decreased in NP & Low \\
\hline \multirow[t]{2}{*}{ Grip et al. [62] } & \multirow{2}{*}{$\begin{array}{l}\text { WAD } 21 \\
\text { INP } 25 \\
\text { C } 24\end{array}$} & Unconstrained & $\begin{array}{l}\text { Speed: As fast as possible } \\
\text { Directions: FLEX/EXT, ROT }\end{array}$ & $\begin{array}{l}\text { Decreased in WAD } \\
\text { Decreased in INP }\end{array}$ & \multirow[t]{2}{*}{ Moderate } \\
\hline & & Functional & $\begin{array}{l}\text { Speed: Given } \\
\text { Task: unpredictable } \\
\text { Function: catching a ball with both } \\
\text { hands at left or right shoulder height }\end{array}$ & $\begin{array}{l}\text { Decreased in WAD } \\
\text { No differences in INP }\end{array}$ & \\
\hline Ohberg et al. [69] & $\begin{array}{l}\text { WAD } 59 \\
\text { C } 56\end{array}$ & Unconstrained & $\begin{array}{l}\text { Speed: As fast as possible } \\
\text { Directions: FLEX/EXT, ROT }\end{array}$ & Decreased in WAD & Moderate \\
\hline Rutledge et al. [72] & $\begin{array}{l}\text { INP } 19 \\
\text { C } 22\end{array}$ & Unconstrained & $\begin{array}{l}\text { Speed: Slow } \\
\text { Directions: LFLEX }\end{array}$ & No significant differences & Moderate \\
\hline Sarig Bahat et al. [74] & $\begin{array}{l}\text { NP } 33 \\
\text { C } 22\end{array}$ & Head aiming; Pointing & $\begin{array}{l}\text { Speed: As fast as possible } \\
\text { Targets: Unpredictable } \\
\text { Directions: FLEX/EXT, ROT }\end{array}$ & Decreased in NP & Moderate \\
\hline Tsang et al. [78] & $\begin{array}{l}\text { INP } 34 \\
\text { C } 34\end{array}$ & Unconstrained & $\begin{array}{l}\text { Speed: Self-preferred } \\
\text { Directions: FLEX/EXT, ROT, LFLEX }\end{array}$ & Decreased in INP & Moderate \\
\hline Vikne et al. [80] & $\begin{array}{l}\text { WAD } 15 \\
\text { C } 15\end{array}$ & Unconstrained & $\begin{array}{l}\text { Speed: Slow }(S), \text { preferred }(P), \text { max } \\
\text { (MAX) } \\
\text { Directions: FLEX/EXT }\end{array}$ & $\begin{array}{l}\text { Decreased in WAD for EFN } \\
\text { and FBN in } S \text { and PDecreased } \\
\text { in WAD for all directions in } \\
\text { MAX }\end{array}$ & Moderate \\
\hline Hage et al. [63] & $\begin{array}{l}\text { INP } 9 \\
\text { C } 15\end{array}$ & Head aiming; Pointing & $\begin{array}{l}\text { Speed: As fast as possible } \\
\text { Targets: Predictable } \\
\text { Directions: ROT }\end{array}$ & No significant differences & High \\
\hline Osterbauer et al. [70] & $\begin{array}{l}\text { WAD } 30 \\
\text { C } 51\end{array}$ & Head aiming; Tracking & $\begin{array}{l}\text { Speed: Self-preferred } \\
\text { Tracking path: Predictable } \\
\text { Pattern: Vertical line }\end{array}$ & Decreased in WAD & High \\
\hline Sarig Bahat et al. [73] & $\begin{array}{l}\text { NP } 25 \\
\text { C } 42\end{array}$ & Head aiming; Pointing & $\begin{array}{l}\text { Speed: As fast as possible } \\
\text { Targets: Unpredictable } \\
\text { Directions: FLEX/EXT, ROT }\end{array}$ & Decreased in NP & High \\
\hline \multicolumn{6}{|l|}{ Peak Velocity } \\
\hline \multicolumn{6}{|c|}{$\begin{array}{l}\text { Summary of findings for NP/INP: } \\
\text { - Inconsistent findings on peak velocity in NP/INP patients compared to healthy controls } \\
\text { - Level of evidence: conflicting } \\
\text { Summary of findings for WAD: } \\
\text { - Inconsistent findings on peak velocity in WAD patients compared to healthy controls } \\
\text { - Level of evidence: conflicting }\end{array}$} \\
\hline Publication & Sample & Task & Task specifications & Results compared to $C$ & Risk of Bias \\
\hline Baydal-Bertomeu et al. [57] & $\begin{array}{l}\text { WAD } 30 \\
\text { C } 29\end{array}$ & Unconstrained & $\begin{array}{l}\text { Speed: Self-preferred } \\
\text { Direction: FLEX/EXT }\end{array}$ & Decreased in WAD & Moderate \\
\hline Meisingset et al. [67] & $\begin{array}{l}\text { INP } 75 \\
\text { C } 91\end{array}$ & Unconstrained & $\begin{array}{l}\text { Speed: Self-preferred } \\
\text { Directions: FLEX/EXT, ROT, LFLEX }\end{array}$ & Decreased in INP & Moderate \\
\hline Ohberg et al. [69] & $\begin{array}{l}\text { WAD } 59 \\
\text { C } 56\end{array}$ & Unconstrained & $\begin{array}{l}\text { Speed: As fast as possible } \\
\text { Directions: FLEX/EXT, ROT }\end{array}$ & Decreased in WAD & Moderate \\
\hline Röijezon et al. [71] & $\begin{array}{l}\text { INP } 118 \\
\text { C } 51\end{array}$ & Unconstrained & $\begin{array}{l}\text { Speed: As fast as possible } \\
\text { Direction: ROT }\end{array}$ & Decreased in INP & Moderate \\
\hline Sarig Bahat et al. [74] & $\begin{array}{l}\text { NP } 33 \\
\text { C } 22\end{array}$ & Head aiming; Pointing & $\begin{array}{l}\text { Speed: As fast as possible } \\
\text { Targets: Unpredictable } \\
\text { Directions: FLEX/EXT, ROT }\end{array}$ & Decreased in NP & Moderate \\
\hline
\end{tabular}


Table 7 (continued)

\begin{tabular}{|c|c|c|c|c|c|}
\hline Sjölander et al. [76] & $\begin{array}{l}\text { WAD } 7 \\
\text { INP } 9 \\
\text { C16 }\end{array}$ & Unconstrained & $\begin{array}{l}\text { Speed: As fast as possible } \\
\text { Direction: ROT }\end{array}$ & No significant differences & Moderate \\
\hline Takasaki et al. [77] & $\begin{array}{l}\text { WAD } 14 \\
\text { C } 14\end{array}$ & Functional & $\begin{array}{l}\text { Speed: Self-preferred } \\
\text { Task: Unpredictable } \\
\text { Function: Driving simulator in } 3 \text { differ- } \\
\text { ent traffic scenarios }\end{array}$ & No significant differences & Moderate \\
\hline Tsang et al. [79] & $\begin{array}{l}\text { INP } 30 \\
\text { C } 30\end{array}$ & Functional & $\begin{array}{l}\text { Speed: Self- preferred } \\
\text { Task: Predictable } \\
\text { Function: Lifting a } 2 \mathrm{~kg} \text { weight by one } \\
\text { hand from a desk to a shelf }\end{array}$ & Decreased in INP & Moderate \\
\hline Vikne et al. [80] & $\begin{array}{l}\text { WAD } 15 \\
\text { C } 15\end{array}$ & Unconstrained & $\begin{array}{l}\text { Speed: Slow(S), preferred }(P), \max \\
(\text { MAX) } \\
\text { Directions: FLEX/EXT }\end{array}$ & $\begin{array}{l}\text { Decreased in WAD for EFN } \\
\text { and FBN in S and PDecreased } \\
\text { in WAD for all directions in } \\
\text { MAX }\end{array}$ & Moderate \\
\hline Hage et al. [63] & $\begin{array}{l}\text { INP } 9 \\
\text { C } 15\end{array}$ & Head aiming; Pointing & $\begin{array}{l}\text { Speed: As fast as possible } \\
\text { Targets: Predictable } \\
\text { Directions: ROT }\end{array}$ & No significant differences & High \\
\hline Sarig Bahat et al. [73] & $\begin{array}{l}\text { NP } 25 \\
\text { C } 42\end{array}$ & Head aiming; Pointing & $\begin{array}{l}\text { Speed: As fast as possible } \\
\text { Targets: Unpredictable } \\
\text { Directions: FLEX/EXT, ROT }\end{array}$ & Decreased in NP & High \\
\hline Yang et al. [82] & $\begin{array}{l}\text { NP } 18 \\
\text { C } 18\end{array}$ & Unconstrained & $\begin{array}{l}\text { Speed: Self-preferred } \\
\text { Direction: Circumduction }\end{array}$ & No significant differences & High \\
\hline \multicolumn{6}{|c|}{ Normalized Peak Amplitude } \\
\hline \multicolumn{6}{|c|}{$\begin{array}{l}\text { Summary of findings for INP: } \\
\text { - No difference on normalized peak amplitude in INP patients compared to healthy controls } \\
\text { - Level of evidence: limited }\end{array}$} \\
\hline Publication & Sample & Task & Task specifications & Results compared to $C$ & Risk of Bia \\
\hline Röijezon et al. [71] & INP 118 C 51 & Unconstrained & $\begin{array}{l}\text { Speed: As fast as possible } \\
\text { Direction: ROT }\end{array}$ & No significant differences & Moderate \\
\hline
\end{tabular}

C controls, EFN Extension from neutral position, EXT Extension, F fast, FBN Flexion back to neutral position, FLEX Flexion, INP idiopathic neck pain, LFLEX Lateralflexion, $M A X$ maximal, NP unclassified neck pain, $P$ preferred, ROT Rotation, $S$ slow, WAD whiplash associated disorder

Across all acceleration variables and NP groups, unconstrained movement tasks showed a moderate level of evidence of being reduced [57, 78, 80, 83], while for functional or head aiming task such an effect could not be demonstrated $[63,79]$.

\section{Temporal variables (Table 9)}

Six studies examined the movement time needed to complete a movement task [58, 60, 61, 75, 82, 83]. In five of these studies and for INP and unclassified NP, a strong level of evidence for an increased movement time was found [58, 60, 75, 82, 83]. In contrast, three studies on WAD, showed inconsistent findings, that lead to a conflicting level of evidence $[60,61,75]$. Three studies looked at the reaction time to initiate a movement task $[61,69,74]$. A moderate level of evidence could be demonstrated for an increased reaction time in WAD $[61,69]$, while for unclassified NP a very limited evidence for no differences was found by one study with a high RoB [73]. One study provided a limited level of evidence for an increased deceleration phase and no differences in acceleration phase duration in patients with INP [58]. Four studies examined a ratio of phase duration and provided limited level of evidence for WAD [80], and conflicting level of evidence for INP and unclassified NP [71, 73, 74].

\section{Movement smoothness: (Table 10)}

Eleven studies examined eight outcome variables and demonstrated a limited, very limited or conflicting level of evidence [57, 66, 68, 71, 73, 74, 76, 80-83]. A limited level of evidence could be demonstrated for an increased spectral entropy in unclassified NP [82], an increased speed index of deviation in INP [71], and an increased root mean square velocity in WAD [81]. Furthermore, a limited level of evidence of no differences in INP could be found for root mean square jerk [66] and root mean square velocity [81]. A very limited level of evidence was found for an increased number of jerk peaks [83] and spectral entropy [82] in unclassified NP. A conflicting level of evidence existed for normalized jerk cost, for all NP subgroups [68, 76, 80, 83], and for the number of velocity peaks in unclassified NP $[73,74]$.

\section{Movement accuracy (Table 11)}

Movement accuracy was assessed in eight studies and on three outcome variables $[59,60,64,65,67,68,74,75]$. A 
Table 8 Outcome Summary for Acceleration variables

\section{Mean Acceleration}

Summary of findings for INP:

- Decreased mean acceleration in INP patients compared to healthy controls

- Level of evidence: limited

\section{Publication}

Tsang et al. [78]

\section{Sample Task}

INP 34 Unconstrained

C 34

\section{Task specifications}

Speed: Self-preferred

Directions: FLEX/EXT, ROT, LFLEX
Results compared to $C$

Decreased in INP
Risk of Bias

moderate

\section{Peak Acceleration}

Summary of findings for INP:

- Inconsistent findings on peak acceleration in INP patients compared to healthy controls

- Level of evidence: conflicting

Summary of findings for WAD:

- Decreased peak acceleration in WAD patients compared to healthy controls

- Level of evidence: moderate

\section{Publication \\ Sample Task \\ Baydal-Bertomeu et al. [57] WAD 30 Unconstrained C 29 \\ Tsang et al. [79] \\ INP 30 Functional C 30}

Vikne et al. [80]

WAD 15 Unconstrained

Hage et al. [63]

$$
\text { INP } 9
$$$$
\text { C } 15
$$

\section{Task specifications}

Speed: Self-preferred Direction: FLEX/EXT

Speed: Self- preferred Task: Predictable Function: Lifting a $2 \mathrm{~kg}$ weight by one hand from a desk to a shelf

Speed: Slow(S), preferred (P), max (MAX)

Directions: FLEX/EXT

Speed: as fast as possible

Targets: predictable

Directions: ROT

\section{Results compared to C}

Decreased in WAD

Decreased in INP

Decreased in WAD for FBN in SDecreased in WAD for EFN and FBN in PDecreased in WAD for all directions in MAX

No significant differences
Risk of Bias moderate

moderate

moderate

high

\section{Peak Deceleration}

Summary of findings for INP:

- No difference on peak deceleration in INP patients compared to healthy controls

- Level of evidence: very limited

Summary of findings for WAD:

- Decreased peak deceleration in WAD patients compared to healthy controls in maximal speed condition

- Level of evidence: limited

Vikne et al. [80]

WAD 15 Unconstrained

C 15

Speed: Slow(S), preferred (P), max

(MAX)

Directions: FLEX/EXT

Decreased in WAD for EFN in SDecreased in WAD for EFN and FBN in PDecreased in WAD for all directions in MAX

Hage et al. [63]

INP 9 Head aiming; Pointing

Speed: as fast as possible Targets: predictable No significant differences

\section{Magnitude of Circumduction Vectors (MCV)}

Directions: ROT

Summary of findings for NP.

- Decreased MCV in NP patients compared to healthy controls

- Level of evidence: very limited

\section{Publication}

Zhou et al. [83]
Sample Task

NP 28 Unconstrained C 23

\section{Task specifications}

Speed: Self-preferred Direction: Circumduction
Results compared to C

Decreased in NP
Risk of Bias

high

C controls, EFN Extension from neutral position, EXT Extension, F fast, FBN Flexion back to neutral position, FLEX Flexion, INP idiopathic neck pain, LFLEX Lateralflexion, MAX maximal, MCV Magnitude of circumduction vector, NP unclassified neck pain, $P$ preferred, $R O T$ Rotation, $S$ slow, WAD whiplash associated disorder 
Table 9 Outcome Summary for Temporal Variables

\begin{tabular}{|c|c|c|c|c|c|}
\hline \multicolumn{6}{|l|}{ Movement Time } \\
\hline \multicolumn{6}{|c|}{$\begin{array}{l}\text { Summary of findings for NP/INP: } \\
\text { - Increased movement time in NP/ INP patients compared to healthy controls } \\
\text { - Level of evidence: strong } \\
\text { Summary of findings for WAD: } \\
\text { - Inconsistent findings on movement time in WAD patients compared to healthy controls } \\
\text { - Level of evidence: conflicting }\end{array}$} \\
\hline Publication & Sample & Task & Task specifications & Results compared to $C$ & Risk of Bias \\
\hline Ernst et al. [60] & $\begin{array}{l}\text { INP } 25 \\
\text { WAD } 13 \\
\text { C } 38\end{array}$ & $\begin{array}{l}\text { Head aiming; } \\
\text { Tracking }\end{array}$ & $\begin{array}{l}\text { Speed: Self-preferred } \\
\text { Tracking Path: Predictable } \\
\text { Patterns: Figure of eight (F8), Zig Zag } \\
\text { (ZZ) }\end{array}$ & $\begin{array}{l}\text { Increased in INP } \\
\text { No significant differences in WAD }\end{array}$ & low \\
\hline Sarig Bahat et al. [75] & $\begin{array}{l}\text { INP } 12 \\
\text { WAD } 8 \\
\text { C } 20\end{array}$ & $\begin{array}{l}\text { Head aiming; } \\
\text { Tracking }\end{array}$ & $\begin{array}{l}\text { Speed: Self-preferred } \\
\text { Tracking Path: Predictable } \\
\text { Pattern: Zig Zag (ZZ) }\end{array}$ & $\begin{array}{l}\text { Increased in INP } \\
\text { No significant differences in WAD }\end{array}$ & low \\
\hline Descarreaux et al. [58] & $\begin{array}{l}\text { INP } 19 \\
\text { C } 20\end{array}$ & $\begin{array}{l}\text { Head aiming; } \\
\text { Pointing }\end{array}$ & $\begin{array}{l}\text { Speed: As fast as possible } \\
\text { Target: Predictable } \\
\text { Direction: ROT }\end{array}$ & Increased in INP & moderate \\
\hline Gadotti et al. [61] & $\begin{array}{l}\text { WAD } 5 \\
\text { C } 15\end{array}$ & $\begin{array}{l}\text { Head aiming; } \\
\text { Pointing }\end{array}$ & $\begin{array}{l}\text { Speed: As fast as possible } \\
\text { Target: Unpredictable } \\
\text { Direction: ROT }\end{array}$ & Increased in WAD & moderate \\
\hline Yang et al. [82] & $\begin{array}{l}\text { NP } 18 \\
\text { C } 18\end{array}$ & Unconstrained & $\begin{array}{l}\text { Speed: Self-preferred } \\
\text { Direction: Circumduction }\end{array}$ & Increased in NP & high \\
\hline Zhou et al. [83] & $\begin{array}{l}\text { NP } 28 \\
\text { C } 23\end{array}$ & Unconstrained & $\begin{array}{l}\text { Speed: Self-preferred } \\
\text { Direction: Circumduction }\end{array}$ & Increased in NP & high \\
\hline \multicolumn{6}{|l|}{ Reaction Time } \\
\hline \multicolumn{6}{|c|}{$\begin{array}{l}\text { Summary of findings for NP: } \\
\text { - No differences on reaction time in NP patients compared to healthy controls } \\
\text { - Level of evidence: very limited } \\
\text { Summary of findings for WAD: } \\
\text { - Increased reaction time in WAD patients compared to healthy controls } \\
\text { - Level of evidence: } \text { moderate* }\end{array}$} \\
\hline Publication & Sample & Task & Task specifications & Results compared to $C$ & Risk of Bias \\
\hline Gadotti et al. [61] & $\begin{array}{l}\text { WAD } 5 \\
\text { C } 15\end{array}$ & $\begin{array}{l}\text { Head aiming; } \\
\text { Pointing }\end{array}$ & $\begin{array}{l}\text { Speed: As fast as possible } \\
\text { Target: Unpredictable } \\
\text { Direction: ROT }\end{array}$ & Increased in WAD & moderate \\
\hline Ohberg et al. [69] & $\begin{array}{l}\text { WAD } 59 \\
\text { C } 56\end{array}$ & Unconstrained & $\begin{array}{l}\text { Speed: As fast as possible } \\
\text { Directions: FLEX/EXT, ROT }\end{array}$ & Increased in WAD & moderate \\
\hline Sarig Bahat et al. [73] & $\begin{array}{l}\text { NP } 25 \\
\text { C } 42\end{array}$ & $\begin{array}{l}\text { Head aiming; } \\
\text { Pointing }\end{array}$ & $\begin{array}{l}\text { Speed: As fast as possible } \\
\text { Targets: Unpredictable } \\
\text { Directions: FLEX/EXT, ROT }\end{array}$ & No significant differences & high \\
\hline \multicolumn{6}{|c|}{ Acceleration Phase Duration } \\
\hline \multicolumn{6}{|c|}{$\begin{array}{l}\text { Summary of findings for INP: } \\
\text { - No differences in acceleration phase duration in NP patients compared to healthy controls } \\
\text { - Level of evidence: limited }\end{array}$} \\
\hline Publication & Sample & Task & Task specifications & Results compared to $C$ & Risk of Bias \\
\hline Descarreaux et al. [58] & $\begin{array}{l}\text { INP } 19 \\
\text { C } 20\end{array}$ & $\begin{array}{l}\text { Head aiming; } \\
\text { Pointing }\end{array}$ & $\begin{array}{l}\text { Speed: As fast as possible } \\
\text { Target: Predictable } \\
\text { Direction: ROT }\end{array}$ & No significant differences & moderate \\
\hline \multicolumn{6}{|c|}{ Deceleration Phase Duration } \\
\hline \multicolumn{6}{|c|}{$\begin{array}{l}\text { Summary of finding: } \\
\text { - Increased deceleration phase duration in INP patients compared to healthy controls } \\
\text { - Level of evidence: limited }\end{array}$} \\
\hline Publication & Sample & Task & Task specifications & Results compared to $C$ & Risk of Bias \\
\hline Descarreaux et al. [58] & $\begin{array}{l}\text { INP } 19 \\
\text { C } 20\end{array}$ & $\begin{array}{l}\text { Head aiming; } \\
\text { Pointing }\end{array}$ & $\begin{array}{l}\text { Speed: As fast as possible } \\
\text { Target: Predictable } \\
\text { Direction: ROT }\end{array}$ & Increased in NP & moderate \\
\hline
\end{tabular}


Table 9 (continued)

\begin{tabular}{|c|c|c|c|c|c|}
\hline \multicolumn{6}{|c|}{ Ratio of Phase Durations } \\
\hline \multicolumn{6}{|c|}{$\begin{array}{l}\text { Summary of findings for NP/INP: } \\
\text { - Inconsistent findings on ratio of phase durations in NP/INP patients compared to healthy controls } \\
\text { - Level of evidence: conflicting } \\
\text { Summary of findings for WAD: } \\
\text { - No difference on ratio of phase durations in WAD patients compared to healthy controls } \\
\text { - Level of evidence: limited }\end{array}$} \\
\hline Publication & Sample & Task & Task specifications & Results compared to $C$ & Risk of Bias \\
\hline Röijezon et al. [71] & $\begin{array}{l}\text { INP } 118 \\
\text { C } 51\end{array}$ & Unconstrained & $\begin{array}{l}\text { Speed: As fast as possible } \\
\text { Direction: ROT }\end{array}$ & No significant differences & Moderate \\
\hline Sarig Bahat et al. [74] & $\begin{array}{l}\text { NP } 33 \\
\text { C } 22\end{array}$ & Head aiming; Pointing & $\begin{array}{l}\text { Speed: As fast as possible } \\
\text { Targets: Unpredictable } \\
\text { Directions: FLEX/EXT, ROT }\end{array}$ & $\begin{array}{l}\text { Decreased in NP except for target in } \\
\text { LROT }\end{array}$ & Moderate \\
\hline Vikne et al. [80] & $\begin{array}{l}\text { WAD } 15 \\
\text { C } 15\end{array}$ & Unconstrained & $\begin{array}{l}\text { Speed: Slow(S), Preferred (P),Max } \\
\text { (MAX) } \\
\text { Direction: FLEX/EXT }\end{array}$ & No significant differences & Moderate \\
\hline Sarig Bahat et al. [73] & $\begin{array}{l}\text { NP } 25 \\
\text { C } 42\end{array}$ & Head aiming; Pointing & $\begin{array}{l}\text { Speed: As fast as possible } \\
\text { Targets: Unpredictable } \\
\text { Directions: FLEX/EXT, ROT }\end{array}$ & No significant differences & High \\
\hline
\end{tabular}

C controls, EXT Extension, F8 Figure of eight, FLEX Flexion, INP idiopathic neck pain, MAX maximal, NP unclassified neck pain, $P$ preferred, ROT Rotation, S slow, WAD whiplash associated disorder, ZZ Zig Zag

strong level of evidence was found for an increased number of errors in INP and WAD [60,75]. A moderate level of evidence was found for an increased point deviation $[59,64,65,67,68,74,75]$ and a decreased time on target in WAD $[65,68]$. A limited level of evidence was demonstrated for decreased time on target in INP [65]. A conflicting level of evidence was found for point deviation in unclassified NP $[65,67,74,75]$.

\section{Discussion}

This systematic review aimed to collate various movement tasks and outcome variables, that had been used to examine time-domain related head kinematics and movement accuracy in case control studies comparing patients with NP with asymptomatic controls. Three different movement tasks were employed, head aiming towards a target, performing functional tasks, or moving the head without constraints, as in circumduction or rotation. Strong evidence was found for movement time being increased during the performance of a movement task, such as head tracking, pointing, or unconstrained head movements in patients with NP. Furthermore, there was strong evidence of decreased movement accuracy, in terms of an increased number of errors made during a head tracking task in INP and WAD, when compared to control participants. The latter were only examined in two studies, both demonstrated a low RoB, while the former was investigated in six studies with low to high RoB. Moderate evidence was detected showing decreased mean velocity, a decreased peak acceleration, decreased time on target, increased point deviation and reaction time for patients with WAD compared to healthy controls. In addition, a moderate level of evidence has been found for all acceleration variables during unconstrained movement tasks. Other kinematic and/or movement accuracy variables demonstrated only limited, very limited, or even, conflicting results.

Some of the findings suggest impaired sensorimotor control in NP in respect to their kinematic and movement accuracy abilities, while other findings were dependent on the specific NP subgroup investigated or the specific outcome variable assessed. The overall methodological quality, or risk of bias, of included studies was moderate, as many studies did not provide adequate information to prevent bias, such as selection bias, blinding of study personnel, and confounding, e.g., not matching for age or sex (see Table 3).

Studies showed high clinical and methodological variability. Clinical variability was shown particularly through differences in the definition of the NP status, while methodological variability was found with respect to the movement tasks, including specifications and defined outcomes. These issues, together with the overall RoB, imply that the results of this review should be interpreted with caution, since comparability was limited and accordingly pooling of results for quantitative analysis was not possible.

In addition, all included studies are case-control studies within cross-sectional designs, which limits their generalisability and diagnostic accuracy implied by the potential selection bias within this study design itself [85].

Findings on movement accuracy in patients with WAD were robust, independent of outcome variables used, as patients with WAD showed a reduced movement 
Table 10 Outcome Summary for Movement Smoothness Variables

\section{Normalized Jerk Cost}

Summary of findings for NP/INP:

- Inconsistent findings on normalized jerk cost in NP/ INP patients compared to healthy controls

- Level of evidence: conflicting

Summary of findings for WAD:

- Inconsistent findings on normalized jerk cost in WAD patients compared to healthy controls

- Level of evidence: conflicting

\section{Publication}

Oddsottir et al. [68]

Sjölander et al. [76]

Zhou et al. [83]

Root Mean Square Jerk

Summary of findings for INP:

- No differences on root mean square jerk in INP patients compared to healthy controls

- Level of evidence: limited

Lemmers et al. [66]

$$
\text { INP } 35 \text { Unconstrained }
$$$$
\text { C } 100
$$

WAD 34 Head aiming; Tracking C 31

WAD 7 Unconstrained INP 9

C16

WAD 15 Unconstrained C 15

NP 28 Unconstrained C 23

\section{Task specifications}

Speed: Given for the target cursor Tracking path: Unpredictable Patterns: 3 incremental difficulties

Speed: As fast as possible Direction: ROT

Speed: Slow(S), preferred $(P), \max$ (MAX)

Directions: FLEX/EXT

Speed: Self-preferred

Direction: Circumduction

\section{Results compared to $C$}

Increased in WAD for the easy and medium difficult pattern

Increased in INP for In-Left and Out-Left

Increased in WAD for Out-Left

No significant differences

No significant differences

No significant differences

Speed: Self-preferred

Direction: LFLEX

\section{Number of Jerk Peaks}

Summary of findings for NP:

- Increased number of jerk peaks in NP patients compared to healthy controls

- Level of evidence: very limited

$\begin{array}{lll}\text { Publication } & \text { Sample } & \text { Task } \\ \text { Zhou et al. [83] } & \text { NP 28 } & \text { Unconstrained } \\ & \text { C 23 } & \end{array}$

\section{Task specifications}

Results compared to $C$

Speed: Self-preferred

Direction: Circumduction
Risk of Bias

moderate

moderate

moderate

high

Risk of Bias

high

\section{Root Mean Square Velocity}

Summary of findings for INP.

- No difference on root mean square velocity in INP patients compared to healthy controls

- Level of evidence: limited

summary of findings for WAD:

- Increased root mean square velocity in WAD patients compared to healthy controls in slow and moderate speed conditions

- Level of evidence: limited

Publication

Woodhouse et al. [81]

\section{Sample Task}

WAD 35 Head aiming;

INP 45 Tracking

C 48

\section{Task specifications}

Speed: Slow (S), moderate (MOD), fast (F)

Tracking path: Predictable

Pattern: Figure of eight

\section{Number of Velocity Peaks}

Summary of findings for NP:

- Inconsistent findings on number of velocity peaks in NP patients compared to healthy controls

- Level of evidence: conflicting

\begin{tabular}{|c|c|c|c|}
\hline Publication & Sample & Task & Task specifications \\
\hline Sarig Bahat et al. [74] & $\begin{array}{l}\text { NP } 33 \\
\text { C } 22\end{array}$ & Head aiming; Pointing & $\begin{array}{l}\text { Speed: As fast as possible } \\
\text { Targets: Unpredictable } \\
\text { Directions: FLEX/EXT, ROT }\end{array}$ \\
\hline Sarig Bahat et al. [73] & $\begin{array}{l}\text { NP } 25 \\
\text { C } 42\end{array}$ & Head aiming; Pointing & $\begin{array}{l}\text { Speed: As fast as possible } \\
\text { Targets: Unpredictable } \\
\text { Directions: FLEX/EXT, ROT }\end{array}$ \\
\hline
\end{tabular}

Speed Index of Deviation

Summary of findings for INP:

- Increased speed index of deviation in INP patients compared to healthy controls

- Level of evidence: limited

\section{Results compared to $C$}

Increased in WAD for $S$ and $M O D$ No significant differences in INP
Risk of Bias

Moderate
Results compared to $C$

Increased in NP

Decreased in NP
Risk of Bias

Moderate

High 
Table 10 (continued)

\begin{tabular}{|c|c|c|c|c|c|}
\hline Publication & Sample & Task & Task specifications & Results compared to $C$ & Risk of Bias \\
\hline Röijezon et al. [71] & $\begin{array}{l}\text { INP } 118 \\
\text { C } 51\end{array}$ & Unconstrained & $\begin{array}{l}\text { Speed: As fast as possible } \\
\text { Direction: ROT }\end{array}$ & Increased in INP & moderate \\
\hline \multicolumn{6}{|l|}{ Spectral Entropy } \\
\hline \multicolumn{6}{|c|}{$\begin{array}{l}\text { Summary of findings: } \\
\text { - Increased spectral entropy in NP patients compared to healthy controls } \\
\text { - Level of evidence: very limited }\end{array}$} \\
\hline Publication & Sample & Task & Task specifications & Results compared to $C$ & Risk of Bias \\
\hline Yang et al. [82] & $\begin{array}{l}\text { NP } 18 \\
\text { C } 18\end{array}$ & Unconstrained & $\begin{array}{l}\text { Speed: Self-preferred } \\
\text { Direction: Circumduction }\end{array}$ & Increased in NP & high \\
\hline \multicolumn{6}{|l|}{ Harmonicity } \\
\hline \multicolumn{6}{|c|}{$\begin{array}{l}\text { Summary of findings for WAD: } \\
\text { - No significant differences on harmonicity in WAD patients compared to healthy controls } \\
\text { - Level of evidence: limited }\end{array}$} \\
\hline Publication & Sample & Task & Task specifications & Results compared to $C$ & Risk of Bias \\
\hline Baydal-Bertomeu et al. [57] & $\begin{array}{l}\text { WAD } 30 \\
\text { C } 29\end{array}$ & Unconstrained & $\begin{array}{l}\text { Speed: Self-preferred } \\
\text { Direction: FLEX/EXT }\end{array}$ & No significant differences & moderate \\
\hline
\end{tabular}

C controls, EXT Extension, $F$ fast, $F L E X$ Flexion, INP idiopathic neck pain, LFLEX Lateralflexion, MAX maximal, MOD moderate, NP unclassified neck pain, $P$ preferred, ROT Rotation, $S$ slow, WAD whiplash associated disorder

accuracy with moderate to strong level of evidence. The same seems to be true for movement time in INP and unclassified NP, though not for WAD. However, as time and accuracy within a head aiming task are usually regarded inversely related, known as the speed-accuracy trade-off [86], both outcome measures must be regarded in combination [87]. Accordingly, this association needs to be accounted for in those studies that found differences in movement accuracy measures, but could not, for the same test, demonstrate differences in movement time $[60,75]$. These findings give an indication that patients with WAD may prefer speed to accuracy as a movement strategy, if the task allows for. Unconstrained movement tasks were most frequently used in studies to determine acceleration outcomes [57, 78, 80, 83] and have demonstrated a moderate level of evidence for a decreased acceleration in NP. It seems that, irrespective of further movement specifications, such as speed or displacement, patients with NP differ from controls for acceleration variables. A main effect for other movement tasks on other outcome measures could not be determined. Though, within those three studies that used functional tasks, only velocity and acceleration variables have been examined [62, 77, 79]. Inconsistent or opposing results for some outcome variables, led to conflicting levels of evidence within in our review. Some of these may be explained by insufficient sample sizes to determine a group difference (type II error). This may have occurred for mean-, peak velocity, and movement time, as all studies, that found no differences between NP and controls had sample sizes below twenty $[60,72,77,82]$ or even below ten $[63,76]$ for their NP groups. However, this might not be the case for the velocity variable normalized peak amplitude, as the only study that examined this outcome had the largest sample size with a $n=118$ for the INP group, but could not determine an effect [71]. Lacking of statistical power cannot explain limited and conflicting results for movement smoothness, as most studies had larger sample sizes ( $>20$ per group), and one study even pointed into the opposite direction, as the authors determined a decrease in the number of velocity peaks in NP, while for all other movement smoothness variables either an increase or no differences were reported (Table 10). Opposing results by just one study have also been found for point deviation in studies on movement accuracy [67]. Meisingset et al. interpreted a decreased point deviation as a "stiffening pattern" in INP [67] that, however has not been confirmed in a follow-up study by the same authors [38]. Another study by de Zoete et al. did not report opposing results but found no group differences for that same outcome variable [59].

Our systematic review is, for the most part, in line with recent reviews on further sensorimotor control variables, predominantly joint position sense, examined in NP versus healthy controls [10, 18, 23, 24]. While de Vries' review focussed solely on joint position sense [18], others $[10,23,24]$ reported also on further variables, some similar to our review, such as velocity [10], and movement accuracy [10, 23, 24]. Hesby et al. included ten studies on either peak or "average" velocity, and reported conflicting results too [10]. Some studies found lower velocity values for NP, while other studies did not [10]. Although the authors included studies on WAD, they did not provide separate results for INP and WAD, as we have done, 
Table 11 Outcome Summary for Movement Accuracy Variables

\begin{tabular}{|c|c|c|c|c|c|}
\hline \multicolumn{6}{|l|}{ Number of Errors } \\
\hline \multicolumn{6}{|c|}{$\begin{array}{l}\text { Summary of findings for INP: } \\
\text { - Increased number of errors in INP patients compared to healthy controls } \\
\text { - Level of evidence: strong } \\
\text { Summary of findings for WAD: } \\
\text { - Increased number of errors in WAD patients compared to healthy controls } \\
\text { - Level of evidence: strong }\end{array}$} \\
\hline Publication & Sample & Task & Task specifications & Results compared to $C$ & Risk of Bias \\
\hline Ernst et al. [60] & $\begin{array}{l}\text { INP } 25 \\
\text { WAD } 13 \\
\text { C } 38\end{array}$ & $\begin{array}{l}\text { Head aiming; } \\
\text { Tracking }\end{array}$ & $\begin{array}{l}\text { Speed: Self-preferred } \\
\text { Tracking Path: Predictable } \\
\text { Patterns: Figure of eight (F8), Zig Zag } \\
\text { (ZZ) }\end{array}$ & $\begin{array}{l}\text { Increased in INP } \\
\text { Increased in WAD }\end{array}$ & low \\
\hline Sarig Bahat et al. [75] & $\begin{array}{l}\text { INP } 12 \\
\text { WAD } 8 \\
\text { C } 20\end{array}$ & $\begin{array}{l}\text { Head aiming; } \\
\text { Tracking }\end{array}$ & $\begin{array}{l}\text { Speed: Self-preferred } \\
\text { Tracking Path: Predictable } \\
\text { Pattern: Zig Zag (ZZ) }\end{array}$ & $\begin{array}{l}\text { Increased in INP } \\
\text { Increased in WAD }\end{array}$ & low \\
\hline \multicolumn{6}{|l|}{ Point Deviation } \\
\hline \multicolumn{6}{|c|}{$\begin{array}{l}\text { Summary of findings in NP/INP: } \\
\text { - Inconsistent findings on point deviation in NP/ INP patients compared to he } \\
\text { - Level of evidence: conflicting } \\
\text { Summary of findings in WAD: } \\
\text { - Increased point deviation in WAD patients compared to healthy controls } \\
\text { - Level of evidence: } \text { moderate }\end{array}$} \\
\hline Publication & Sample & Task & Task specifications & Results compared to $C$ & Risk of Bias \\
\hline Sarig Bahat et al. [75] & $\begin{array}{l}\text { INP } 12 \\
\text { WAD } 8 \\
\text { C } 20\end{array}$ & $\begin{array}{l}\text { Head aiming; } \\
\text { Tracking }\end{array}$ & $\begin{array}{l}\text { Speed: Given for the target cursor } \\
\text { Tracking Path: Unpredictable } \\
\text { Pattern: Horizontal and vertical line }\end{array}$ & $\begin{array}{l}\text { Increased in INP for horizontal direc- } \\
\text { tions } \\
\text { Increased in WAD for all directions }\end{array}$ & low \\
\hline De Zoete et al. [59] & $\begin{array}{l}\text { INP } 50 \\
\text { C } 50\end{array}$ & $\begin{array}{l}\text { Head aiming; } \\
\text { Tracking }\end{array}$ & $\begin{array}{l}\text { Speed: Given for the target cursor } \\
\text { Tracking path: Unpredictable }\end{array}$ & No significant differences & low \\
\hline Kristjansson et al. [64] & $\begin{array}{l}\text { WAD } 20 \\
\text { C } 20\end{array}$ & $\begin{array}{l}\text { Head aiming; } \\
\text { Tracking }\end{array}$ & $\begin{array}{l}\text { Speed: Given for the target cursor } \\
\text { Tracking path: Unpredictable }\end{array}$ & Increased in WAD & moderate \\
\hline Kristjansson and Oddsdottir et al. [65] & $\begin{array}{l}\text { WAD } 18 \\
\text { INP } 18 \\
\text { C } 18\end{array}$ & $\begin{array}{l}\text { Head aiming; } \\
\text { Tracking }\end{array}$ & $\begin{array}{l}\text { Speed: Given for the target cursor } \\
\text { Tracking path: Unpredictable }\end{array}$ & $\begin{array}{l}\text { Increased in WAD } \\
\text { Increased in INP }\end{array}$ & moderate \\
\hline Meisingset et al. [67] & $\begin{array}{l}\text { INP } 75 \\
\text { C } 91\end{array}$ & $\begin{array}{l}\text { Head aiming; } \\
\text { Tracking }\end{array}$ & $\begin{array}{l}\text { Speed: Given for the target cursor, low } \\
\text { speed and high speed } \\
\text { A) } \\
\text { Tracking path: Predictable } \\
\text { Pattern: Figure of eight } \\
\text { B) } \\
\text { Tracking path: Unpredictable } \\
\text { Patterns: Two incremental difficulties }\end{array}$ & $\begin{array}{l}\text { Decreased in INP in high speed sitting } \\
\text { and low speed standing in A) } \\
\text { Decreased in INP for the easy pattern } \\
\text { in B) }\end{array}$ & moderate \\
\hline Oddsottir et al. [68] & $\begin{array}{l}\text { WAD } 34 \\
\text { C } 31\end{array}$ & $\begin{array}{l}\text { Head aiming; } \\
\text { Tracking }\end{array}$ & $\begin{array}{l}\text { Speed: Given for the target cursor } \\
\text { Tracking path: Unpredictable }\end{array}$ & Increased in WAD & moderate \\
\hline Sarig Bahat et al. [74] & $\begin{array}{l}\text { NP } 33 \\
\text { C } 22\end{array}$ & $\begin{array}{l}\text { Head aiming; } \\
\text { Tracking }\end{array}$ & $\begin{array}{l}\text { Speed: Given for the target cursor } \\
\text { Tracking Path: Unpredictable } \\
\text { Pattern: Horizontal and vertical line }\end{array}$ & Increased in NP & moderate \\
\hline \multicolumn{6}{|l|}{ Time on Target } \\
\hline \multicolumn{6}{|c|}{$\begin{array}{l}\text { Summary of findings for INP: } \\
\text { - Decreased time on target in INP patients compared to healthy controls } \\
\text { - Level of evidence: limited } \\
\text { Summary of findings for WAD: } \\
\text { - Decreased time on target in WAD patients compared to healthy controls } \\
\text { - Level of evidence: moderate }\end{array}$} \\
\hline Publication & Sample & Task & Task specifications & Results compared to $C$ & Risk of Bias \\
\hline Kristjansson and Oddsdottir et al. [65] & $\begin{array}{l}\text { WAD } 18 \\
\text { INP } 18 \\
\text { C } 18\end{array}$ & $\begin{array}{l}\text { Head aiming; } \\
\text { Tracking }\end{array}$ & $\begin{array}{l}\text { Speed: Given for the target cursor } \\
\text { Tracking path: Unpredictable }\end{array}$ & $\begin{array}{l}\text { Decreased in WAD } \\
\text { Decreased in INP }\end{array}$ & moderate \\
\hline Oddsottir et al. [68] & $\begin{array}{l}\text { WAD } 34 \\
\text { C } 31\end{array}$ & $\begin{array}{l}\text { Head aiming; } \\
\text { Tracking }\end{array}$ & $\begin{array}{l}\text { Speed: Given for the target cursor } \\
\text { Tracking path: Unpredictable }\end{array}$ & Decreased in WAD & moderate \\
\hline
\end{tabular}

C controls, F8 Figure of eight, INP idiopathic neck pain, NP unclassified neck pain, WAD whiplash associated disorder, ZZ Zig Zag 
if possible [10]. Within our review, we could determine a moderate level of evidence for a decreased mean velocity in WAD, provided by four studies [62, 69, 70, 80], of which only one had been included in Hesby et al's review too [10]. Movement accuracy studies have been examined by all three reviews [10, 23, 24]. They included two [23], three [24], or four primary studies respectively [10], all of them have also been included in this review [64, 65, 67, 74], and led, together with additional four studies, to a strong level of evidence for an increased number of errors in INP and WAD, while performing a head aiming (tracking) task (Table 11). Furthermore, an additional review by Moghaddas et al. focused solely on kinematics during functional movements, [22]. That review finally included five primary studies [22] of which two, assessing timedomain related kinematics, have also been included in our review $[73,79]$. However, we regarded one of those as performing a head aiming, instead of a functional task [73]. In summary, most sensorimotor control variables examined in aforementioned reviews, demonstrated only little discriminatory validity such as for joint position sense [10, $18,24]$ or postural stability [24]. The current review adds to research on sensorimotor control in NP and its expression within kinematic quantities, and movement accuracy. Moreover, it gives more distinct reference to the kind of movement task and outcome variables to be examined within their superior kinematic quantity.

\section{Strength and limitations}

A strength of this review is the well-documented and methodological approach to a field of study troubled by high heterogeneity and uncertainties. Furthermore, the literature search was intentionally broad to be as encompassing as possible. Therefore, this review includes acute and chronic NP. However, most included articles reported on NP with a duration of 6 weeks or longer, so generalization and applicability to an acute NP condition remains limited. Another consequence of the broad literature search strategy was to include NP with both idiopathic and whiplash associated onset.

If possible, findings for kinematics and movement accuracy were presented separately for patients with WAD and INP. However, not all studies specified on whiplash grades according to the Quebec task force classification [84]. For those studies that did not distinguish WAD and INP, results were summarized as unclassified NP, and added to INP comparisons, which could have biased results for these outcome variables and NP groups. However, and as has been discussed before, for some outcome variables this review could demonstrate larger sensorimotor control differences in patients with WAD when compared to controls.
The level of evidence for summary findings was defined by a slightly adapted version of a classification system presented by the method guidelines for systematic reviews in the Cochrane collaboration Back Review Group [56]. According to both, the original and the adapted system, the level of evidence would classify as 'conflicting' if studies had showed opposing results, independent of the number or quality of these studies. In general, this has led to a stricter interpretation of results, since only one contradicting study would lead to a conflicting level of evidence rating. This approach has been favoured due to the heterogeneity of the studies and to be cautious in generalising the findings from kinematics and movement accuracy in patients with NP and WAD across tasks.

There are some limitations to this review. Due to the lack of an appropriate and validated RoB tool for cross sectional case control studies, and since there is no reference standard for assessing head kinematics or movement accuracy, an existing RoB tool that has been used in reviews with similar topics to this one [22, 24] was adapted for the purpose of this review [53]. This adapted version has not been validated, which limits comparison to other reviews. Nevertheless, the interrater reliability between the two reviewers was high and a detailed description of the tailoring process, as provided in the appendices, ensures reproducibility of the quality assessment. Furthermore, no weighting according to sample and effect sizes was included for quality assessment, which would have increased the precision of the quality rating.

Another limitation is that only statistically significant group differences have been considered, without discussion of their clinical relevance. Additionally, no generalized cut off values were presented for the determination of abnormal head motion kinematics or movement accuracy values between groups. Owing to the heterogeneity of included studies, as mentioned before, this was not regarded possible. Therefore, the practical benefit to clinicians is limited at this stage of research.

Finally, one limitation derives from the nature or entity of the topic itself, as previously mentioned. The high variability between included studies for movement tasks and outcome variables, and further specifications for both, combined with differing measurement technologies used, makes it difficult to draw firm conclusions on head kinematics or movement accuracy in NP.

\section{Implications for future research and clinical practice}

Future research should standardize the measurements for the assessment of head motion kinematics, which would establish a base for the replication of methods to 
validate previous results. Furthermore, to increase confidence in the evidence, the focus should be on improving the methodological quality of studies. Sampling must include a detailed description of the screening procedure and participation rate. The included population should not differ between the groups, except for the condition under study. Furthermore, an a priori sample size should be determined. Measurement procedures need to be described in detail and should include test results from reliability studies. Furthermore, interactions between movement characteristics, such as velocity, displacement and direction need to be reported. Data analysis should be performed with group blinding. Matching, or statistical stratification, for confounding factors should be implemented. Studies are needed that relate kinematic and movement accuracy outcome variables to patient reported outcome variables, such as pain or disability.

Clinicians should consider the movement task which might be used within their setting, along with specifications. This also depends on the availability of technology, which might not be given in all settings. In addition, the evidence from longitudinal studies on the responsiveness of some kinematic or movement accuracy measures and in relation to changes in pain and disability is still controversial $[27,35,38]$.

\section{Conclusion}

Sensorimotor control in NP in the way of kinematic and movement accuracy characteristics of head motion was examined in head aiming, functional or unconstrained movement tasks.

Specific outcome variables under investigation, describe characteristics of velocity and acceleration, temporal characteristics, movement smoothness, and movement accuracy. The methodological quality of included studies was moderate and confidence in the level of evidence for outcomes ranged from strong to conflicting.

The results from this review indicate that for some characteristics that describe sensorimotor control, patients with NP differ from healthy controls, as strong evidence has been found for patients with INP and WAD to deviate more often from a tracking path than controls, with further strong evidence showing, that patients with INP need more time to complete a movement task. Moderate evidence indicates that acceleration in general, and during unconstrained movement tasks in NP, and specifically reaction time, mean velocity, peak acceleration as well as point deviation and time on a target differ between patients with WAD and controls, while movement smoothness variables have not been found to differ between patients with NP and control participants, so far.
Abbreviations

NP: Unclassified neck pain; INP: Idiopathic neck pain; RoB: Risk of bias; WAD: Whiplash associated disorder.

\section{Supplementary Information}

The online version contains supplementary material available at https://doi. org/10.1186/s12891-022-05097-z.

Additional file 1. Search strategy used for MEDLINE database

Additional file 2. Adapted version of the Quality Assessment Tool for Observational Cohort and Cross-Sectional Studies

\section{Acknowledgements}

The authors would like to thank Dr. Lutz Semig and Dr. Christian Freiburghaus for advice on kinematics and Harald Vikne for providing further explanations. We thank Karen Linwood and Sara Mascarello for further editing and proof-reading.

Furthermore, we are extremely grateful to our families for their open ears and patience during the process of this work.

\section{Authors' contributions}

All the presented data were collected by EF and MS jointly. MS converted the extracted data into outcome Tables. EF, CMB and MJE were major contributors to writing the manuscript. Appraisal and data synthesizing were carried out by EF, CMB and MJE. All authors read and approved the final manuscript.

\section{Authors' information}

EF and MS work as physiotherapists in private physiotherapy clinics with qualifications in musculoskeletal rehabilitation. CMB and MJE are Research fellows at the Institute of Physiotherapy at the Zurich University of Applied Sciences, Winterthur, Switzerland.

\section{Funding}

No funding was received for the study.

Availability of data and materials

All data are available at the ZHAW (Zurich University of Applied Sciences) on application to the corresponding author, Markus J. Ernst (markus. ernst@zhaw.ch).

\section{Declarations}

Ethics approval and consent to participate

Approval from an ethics committee was not required for this study due to its design as a review.

\section{Consent for publication}

Not applicable.

\section{Competing interests}

The authors declare that they have no competing interests.

Received: 19 August 2021 Accepted: 8 February 2022 Published: 16 February 2022

References

1. Cohen SP, Hooten WM. Advances in the diagnosis and management of neck pain. BMJ. 2017;358:j3221.

2. Fejer R, Kyvik KO, Hartvigsen J. The prevalence of neck pain in the world population: a systematic critical review of the literature. Eur Spine J. 2006;15(6):834-48.

3. Fejer R, Hartvigsen J. Neck pain and disability due to neck pain: what is the relation? Eur Spine J. 2008;17(1):80-8. 
4. Thoomes EJ, van Geest S, van der Windt DA, Falla D, Verhagen AP, Koes BW, et al. Value of physical tests in diagnosing cervical radiculopathy: a systematic review. Spine J. 2018;18(1):179-89.

5. Jette AM, Delitto A. Physical therapy treatment choices for musculoskeletal impairments. Phys Ther. 1997;77(2):145-54

6. Parikh P, Santaguida P, Macdermid J, Gross A, Eshtiaghi A. Comparison of CPG's for the diagnosis, prognosis and management of non-specific neck pain: a systematic review. BMC Musculoskelet Disord. 2019;20(1):81.

7. Ludvigsson ML, Peterson G, Dedering Å, Falla D, Peolsson A. Factors associated with pain and disability reduction following exercise interventions in chronic whiplash. Eur J Pain. 2016;20(2):307-15.

8. Falla D, O'Leary S, Farina D, Jull G. The change in deep cervical flexor activity after training is associated with the degree of pain reduction in patients with chronic neck pain. Clin J Pain. 2012;28(7):628-34.

9. Jull G, Falla D, Treleaven J, O'Leary S. Managment of neck pain disorders. 1st ed: Elsevier; 2018

10. Hesby BB, Hartvigsen J, Rasmussen H, Kjaer P. Electronic measures of movement impairment, repositioning, and posture in people with and without neck pain-a systematic review. Syst Rev. 2019;8(1):220.

11. Woodhouse A, Vasseljen O. Altered motor control patterns in whiplash and chronic neck pain. BMC Musculoskelet Disord. 2008;9(1):90.

12. O'Leary S, Jull G, Kim M, Vicenzino B. Cranio-cervical flexor muscle impairment at maximal, moderate, and low loads is a feature of neck pain. Man Ther. 2007;12:34-9.

13. Riemann BL, Lephart SM. The sensorimotor system, part I: the physiologic basis of functional joint stability. J Athl Train. 2002;37(1):71-9.

14. Giffard P, Daly L, Treleaven J. Influence of neck torsion on near point convergence in subjects with idiopathic neck pain. Musculoskelet Sci Pract. 2017;32:51-6.

15. Michaelson P, Michaelson M, Jaric S, Latash ML, Sjölander P, Djupsjöbacka M. Vertical posture and head stability in patients with chronic neck pain. J Rehabil Med. 2003;35(5):229-35.

16. Treleaven J, Jull G, Grip H. Head eye co-ordination and gaze stability in subjects with persistent whiplash associated disorders. Man Ther. 2011;16:252-7.

17. Treleaven J, Takasaki H, Grip H. Altered trunk head co-ordination in those with persistent neck pain. Musculoskelet Sci Pract. 2019;39:45-50.

18. de Vries J, Ischebeck BK, Voogt LP, van der Geest JN, Janssen M, Frens MA, et al. Joint position sense error in people with neck pain: a systematic review. Man Ther. 2015;20(6):736-44.

19. Woodhouse A, Liljeback P, Vasseljen O. Reduced head steadiness in whiplash compared with non-traumatic neck pain. J Rehabil Med. 2010;42:35-41.

20. Sarig Bahat $H$, Takasaki H, Chen X, Bet-Or Y, Treleaven J. Cervical kinematic training with and without interactive VR training for chronic neck pain - a randomized clinical trial. Man Ther. 2015;20(1):68-78.

21. Winter DA. Biomechanics and motor control of human movement. 4th ed. New Jersey: John Wiley \& Sons; 2009

22. Moghaddas D, de Zoete RMJ, Edwards S, Snodgrass SJ. Differences in the kinematics of the cervical and thoracic spine during functional movement in individuals with or without chronic neck pain: a systematic review. Physiotherapy. 2019;105(4):421-33.

23. Michiels S, De Hertogh W, Truijen S, November D, Wuyts F, Van de Heyning P. The assessment of cervical sensory motor control: a systematic review focusing on measuring methods and their clinimetric characteristics. Gait \& posture. 2013;38:1-7.

24. de Zoete RMJ, Osmotherly PG, Rivett DA, Farrell SF, Snodgrass SJ. Sensorimotor control in individuals with idiopathic neck pain and healthy individuals: a systematic review and Meta-analysis. Arch Phys Med Rehabil. 2017;98(6):1257-71.

25. Moher D, Liberati A, Tetzlaff J, Altman DG, Group P. Preferred reporting items for systematic reviews and meta-analyses: the PRISMA statement. J Clin Epidemiol. 2009;62(10):1006-12.

26. Alsultan F, Cescon C, De Nunzio AM, Barbero M, Heneghan NR, Rushton $A$, et al. Variability of the helical axis during active cervical movements in people with chronic neck pain. Clin Biomech (Bristol, Avon). 2019;62:50-7

27. Bahat HS, Croft K, Hoddinott A, Carter C, Treleaven J. Remote kinematic e-training for patients with chronic neck pain, a randomised controlled trial. Man Ther. 2016;25:e35.
28. Sarig Bahat H, Sprecher E, Sela I, Treleaven J. Neck motion kinematics: an inter-tester reliability study using an interactive neck VR assessment in asymptomatic individuals. Eur Spine J. 2016;25(7):2139-48.

29. de Zoete RMJ, Osmotherly PG, Rivett DA, Snodgrass SJ. Cervical sensorimotor control does not change over time and is not related to chronic idiopathic neck pain characteristics: a 6-month longitudinal observational study. Phys Ther. 2020;100(2):268-82.

30. Geisinger D, Ferreira E, Suarez A, Suarez H. Dynamic modeling and experimental results for a head tilt response. Annu Int Conf IEEE Eng Med Biol Soc. 2010;2010:2986-9.

31. Gonçalves C, Silva AG. Reliability, measurement error and construct validity of four proprioceptive tests in patients with chronic idiopathic neck pain. Musculoskelet Sci Pract. 2019;43:103-9.

32. Grip H, Jull G, Treleaven J. Head eye co-ordination using simultaneous measurement of eye in head and head in space movements: potential for use in subjects with a whiplash injury. J Clin Monit Comput. 2009;23(1):31-40.

33. Jull G, Amiri M, Bullock-Saxton J, Darnell R, Lander C. Cervical musculoskeletal impairment in frequent intermittent headache. Part 1: subjects with single headaches. Cephalalgia. 2007:27(7):793-802.

34. Kristjansson E, Dall'Alba P, Jull G. Cervicocephalic kinaesthesia: reliability of a new test approach. Physiother Res Int. 2001;6(4):224-35.

35. Kristjansson E, Björnsdottir SV, Oddsdottir GL. The long-term course of deficient cervical kinaesthesia following a whiplash injury has a tendency to seek a physiological homeostasis. Man Ther. 2016;22:196-201.

36. Lascurain-Aguirrebeña I, Newham DJ, Galarraga-Gallastegui B, Critchley DJ. Differences in neck surface electromyography, kinematics and pain occurrence during physiological neck movements between neck pain and asymptomatic participants. A cross-sectional study. Clin Biomech (Bristol, Avon). 2018;57:1-9.

37. Meisingset I, Stensdotter AK, Woodhouse A, Vasseljen O. Changes in neck motion and motor control and associations with neck pain in patients with non-specific neck pain. Physiotherapy. 2015;101:e994.

38. Meisingset I, Stensdotter AK, Woodhouse A, Vasseljen O. Neck motion, motor control, pain and disability: a longitudinal study of associations in neck pain patients in physiotherapy treatment. Man Ther. 2016;22:94-100.

39. Oddsdottir GL, Kristjansson E. Two different courses of impaired cervical kinaesthesia following a whiplash injury. Manl Ther. 2012;17(1):60-5.

40. Röijezon U, Björklund M, Bergenheim M, Djupsjöbacka M. A novel method for neck coordination exercise--a pilot study on persons with chronic non-specific neck pain. J Neuroeng Rehabil. 2008;5:36.

41. Rudolfsson T, Djupsjöbacka M, Häger C, Björklund M. Effects of neck coordination exercise on sensorimotor function in chronic neck pain: a randomized controlled trial. J Rehabil Med. 2014;46(9):908-14.

42. Saadat M, Salehi R, Negahban H, Shaterzadeh MJ, Mehravar M, Hessam M. Traditional physical therapy exercises combined with sensorimotor training: the effects on clinical outcomes for chronic neck pain in a doubleblind, randomized controlled trial. J Bodyw Mov Ther. 2019;23(4):901-7.

43. Bahat HS, Weiss PL, Sprecher E, Krasovsky A, Laufer Y. Do neck kinematics correlate with pain intensity, neck disability or with fear of motion? Man Ther. 2014;19(3):252-8.

44. Sarig Bahat H, Croft K, Carter C, Hoddinott A, Sprecher E, Treleaven J. Remote kinematic training for patients with chronic neck pain: a randomised controlled trial. Eur Spine J. 2018;27(6):1309-23.

45. Treleaven J, Croft K, Carter C, Hoddinott A, Sarig-Bahat H. Are functional complaints relating to neck motion related to altered cervical kinematics in those with neck pain? Musculoskelet Sci Pract. 2017;28:e12.

46. Treleaven J, Chen $X$, Sarig Bahat H. Factors associated with cervical kinematic impairments in patients with neck pain. Man Ther. 2016;22:109-15.

47. Tsang SM, Szeto GP, Lee RY. Relationship between neck acceleration and muscle activation in people with chronic neck pain: implications for functional disability. Clin Biomech (Bristol, Avon). 2016;35:27-36.

48. Waeyaert $P$, Jansen D, Bastiaansen M, Scafoglieri A, Buyl R, Schmitt M, et al. Three-dimensional cervical movement characteristics in healthy subjects and subgroups of chronic neck pain patients based on their pain location. Spine (Phila Pa 1976). 2016;41(15):E908-e914.

49. Werner IM, Ernst MJ, Treleaven J, Crawford RJ. Intra and interrater reliability and clinical feasibility of a simple measure of cervical movement sense in patients with neck pain. BMC Musculoskelet Disord. 2018;19(1):358. 
50. Williams G, Sarig-Bahat H, Williams K, Tyrrell R, Treleaven J. Cervical kinematics in patients with vestibular pathology vs. patients with neck pain: a pilot study. J Vestib Res : Equilib Orientat. 2017;27(2-3):137-45.

51. Woltring HJ, Long K, Osterbauer PJ, Fuhr AW. Instantaneous helical axis estimation from 3-D video data in neck kinematics for whiplash diagnostics. J Biomech. 1994;27(12):1415-32.

52. Zito G, Jull G, Story I. Clinical tests of musculoskeletal dysfunction in the diagnosis of cervicogenic headache. Man Ther. 2006;11(2):118-29.

53. $\mathrm{NIH}$ : quality assessment tool for observational cohort and cross-sectional studies. 2014. http://www.nhlbi.nih.gov/health-topics/study-quality-asses sment-tools.

54. Rohatgi A:WebPlotDigitizer. 2019. http://www.automeris.io/WebPlotDig itizer/.

55. Drevon D, Fursa SR, Malcolm AL. Intercoder reliability and validity of WebPlotDigitizer in extracting graphed data. Behav Modif. 2017;41(2):323-39.

56. van Tulder M, Furlan A, Bombardier C, Bouter L. Group EBotCCBR: updated method guidelines for systematic reviews in the cochrane collaboration back review group. Spine (Phila Pa 1976). 2003;28(12):1290-9.

57. Baydal-Bertomeu JM, Page AF, Belda-Lois JM, Garrido-Jaen D, Prat JM. Neck motion patterns in whiplash-associated disorders: quantifying variability and spontaneity of movement. Clin Biomech (Bristol, Avon). 2011;26:29-34.

58. Descarreaux M, Passmore SR, Cantin V. Head movement kinematics during rapid aiming task performance in healthy and neck-pain participants: the importance of optimal task difficulty. Man Ther. 2010;15:445-50.

59. de Zoete RMJ, Osmotherly PG, Rivett DA, Snodgrass SJ. No differences between individuals with chronic idiopathic neck pain and asymptomatic individuals on 7 cervical sensorimotor control tests: a cross-sectional study. J Orthop Sports Phys Ther. 2020;50(1):33-43.

60. Ernst MJ, Williams L, Werner IM, Crawford RJ, Treleaven J. Clinical assessment of cervical movement sense in those with neck pain compared to asymptomatic individuals. Musculoskelet Sci Pract. 2019;43:64-9.

61. Gadotti I, Hernandez L, Manguson J, Sanchez L, Cevallos F. A pilot study on the evaluation of eye, head, and trunk coordination in subjects with chronic whiplash during a target-tracking task - a driving context approach. Musculoskelet Sci Pract. 2020;46:102124.

62. Grip H, Sundelin G, Gerdle B, Stefan Karlsson J. Cervical helical axis characteristics and its center of rotation during active head and upper arm movements-comparisons of whiplash-associated disorders, non-specific neck pain and asymptomatic individuals. J Biomech. 2008;41(13):2799-805.

63. Hage R, Detrembleur C, Dierick F, Pitance L, Jojczyk L, Estievenart W, et al. DYSKIMOT: An ultra-low-cost inertial sensor to assess Head's rotational kinematics in adults during the Didren-laser test. Sensors (Basel). 2020;20(3)

64. Kristjansson E, Hardardottir L, Asmundardottir M, Gudmundsson K. A new clinical test for cervicocephalic kinesthetic sensibility: "the fly". Arch Phys Med Rehabil. 2004;85:490-5.

65. Kristjansson E, Oddsdottir GL. "the Fly": a new clinical assessment and treatment method for deficits of movement control in the cervical spine: reliability and validity. Spine (Phila Pa 1976). 2010;35:E1298-305.

66. Lemmers GPG, Heijmans MWM, Scafoglieri A, Buyl R, Staal JB, Schmitt MA, et al. Three-dimensional kinematics of the cervical spine using an electromagnetic tracking device. Differences between healthy subjects and subjects with non-specific neck pain and the effect of age. Clin Biomech (Bristol, Avon). 2018;54:111-7.

67. Meisingset I, Woodhouse A, Stensdotter AK, Stavdahl O, Loras H, Gismervik $\mathrm{S}$, et al. Evidence for a general stiffening motor control pattern in neck pain: a cross sectional study. BMC Musculoskelet Disord. 2015;16:56

68. Oddsdottir GL, Kristjansson E, Gislason MK. Sincerity of effort versus feigned movement control of the cervical spine in patients with whiplash-associated disorders and asymptomatic persons: a case-control study. Physiother. 2015;31(6):403-9.

69. Ohberg F, Grip H, Wiklund U, Sterner Y, Karlsson JS, Gerdle B. Chronic whiplash associated disorders and neck movement measurements: an instantaneous helical axis approach. IEEE Trans Inf Technol Biomed. 2003;7:274-82.

70. Osterbauer PJ, Long K, Ribaudo TA, Petermann EA, Fuhr AW, Bigos SJ, et al. Three-dimensional head kinematics and cervical range of motion in the diagnosis of patients with neck trauma. J Manip Physiol Ther. 1996;19:231-7.
71. Roijezon U, Djupsjobacka M, Bjorklund M, Hager-Ross C, Grip H, Liebermann DG. Kinematics of fast cervical rotations in persons with chronic neck pain: a cross-sectional and reliability study. BMC Musculoskelet Disord. 2010;11:222.

72. Rutledge B, Bush TR, Vorro J, Li M, DeStefano L, Gorbis S, et al. Differences in human cervical spine kinematics for active and passive motions of symptomatic and asymptomatic subject groups. J Appl Biomech. 2013;29:543-53.

73. Sarig Bahat $H$, Weiss PL, Laufer $Y$. The effect of neck pain on cervical kinematics, as assessed in a virtual environment. Arch Phys Med Rehabil. 2010;91(12):1884-90.

74. Sarig Bahat H, Chen X, Reznik D, Kodesh E, Treleaven J. Interactive cervical motion kinematics: sensitivity, specificity and clinically significant values for identifying kinematic impairments in patients with chronic neck pain. Man Ther. 2015;20(2):295-302.

75. Sarig Bahat H, Watt P, Rhodes M, Hadar D, Treleaven J. High-vs. low-tech cervical movement sense measurement in individuals with neck pain. Musculoskelet Sci Pract. 2020;45(102097).

76. Sjolander P, Michaelson P, Jaric S, Djupsjobacka M. Sensorimotor disturbances in chronic neck pain--range of motion, peak velocity, smoothness of movement, and repositioning acuity. Man Ther. 2008;13:122-31.

77. Takasaki H, Treleaven J, Johnston V, Van den Hoorn W, Rakotonirainy A, Jull G. A description of neck motor performance, neck pain, fatigue, and mental effort while driving in a sample with chronic whiplash-associated disorders. Am J Phys Med Rehabil. 2014;93:665-74.

78. Tsang SM, Szeto GP, Lee RY. Movement coordination and differential kinematics of the cervical and thoracic spines in people with chronic neck pain. Clin Biomech (Bristol, Avon). 2013;28:610-7.

79. Tsang SM, Szeto GP, Lee RY. Altered spinal kinematics and muscle recruitment pattern of the cervical and thoracic spine in people with chronic neck pain during functional task. J Electromyogr Kinesiol. 2014;24:104-13.

80. Vikne H, Bakke ES, Liestol K, Engen SR, Vollestad N. Muscle activity and head kinematics in unconstrained movements in subjects with chronic neck pain; cervical motor dysfunction or low exertion motor output? BMC Musculoskelet Disord. 2013;14:314.

81. Woodhouse A, Stavdahl O, Vasseljen O. Irregular head movement patterns in whiplash patients during a trajectory task. Exp Brain Res. 2010;201:261-70

82. Yang CC, Su FC, Guo LY. Comparison of neck movement smoothness between patients with mechanical neck disorder and healthy volunteers using the spectral entropy method. Eur Spine J. 2014;23(8):1743-8.

83. Zhou Y, Loh E, Dickey JP, Walton DM, Trejos AL. Development of the circumduction metric for identification of cervical motion impairment. J Rehabil Assist Technol Eng. 2018;5:2055668318777984.

84. Spitzer WO, Skovron ML, Salmi LR, Cassidy JD, Duranceau J, Suissa S, et al. Scientific monograph of the Quebec task force on whiplash-associated disorders: redefining "whiplash" and its management. Spine (Phila Pa 1976). 1995;20(8 Suppl):1S-73S.

85. Whiting PF, Rutjes AW, Westwood ME, Mallett S, Deeks JJ, Reitsma JB, et al. Group Q-: QUADAS-2: a revised tool for the quality assessment of diagnostic accuracy studies. Ann Intern Med. 2011;155(8):529-36.

86. Heitz RP. The speed-accuracy tradeoff: history, physiology, methodology, and behavior. Front Neurosci. 2014;8:150.

87. Fitts PM. The information capacity of the human motor system in controlling the amplitude of movement. J Exp Psychol. 1954;47(6):381-91.

\section{Publisher's Note}

Springer Nature remains neutral with regard to jurisdictional claims in published maps and institutional affiliations. 